\title{
Características e mecanismos de desgaste dos refratários MgO-C usados na linha de escória de panelas de aço
}

\section{(Characteristics and wearing mechanisms of $\mathrm{MgO}-\mathrm{C}$ refractories for steel ladle slag line)}

\author{
F. C. Leite', A.P.Luz ${ }^{2}$, V. C.Pandolfelli ${ }^{2}$ \\ ${ }^{\prime}$ ArcelorMittal Monlevade, Gerência Técnica e Planejamento da Produção \\ ${ }^{2}$ Departamento de Engenharia de Materiais Universidade Federal de S. Carlos, Rod. Washington Luiz, km 235, \\ C.P. 676, S. Carlos, SP, 13565-905 \\ frederico.leite@arcelormittal.com.br,vicpando@ufscar.br
}

\begin{abstract}
Resumo
Panelas de aço são recipientes especiais que transportam o aço líquido desde o final do refino primário até a sua solidificação no lingotamento. Porém, devido à crescente demanda do mercado atual por aços de elevada limpidez, nota-se a freqüiente adoção de novos procedimentos durante a etapa de refino resultando em condições cada vez mais agressivas para o revestimento refratário utilizado nestes equipamentos. Em geral, a região superior da panela onde prevalece o contato entre a escória de aciaria e o refratário (denominada linha de escória), é a mais sujeita ao processo de corrosão e desgaste. Este fato tem implicações significativas na redução da disponibilidade de panelas na produção, necessidade de reparos intermediários no revestimento, além de aumentar os custos produtivos e reduzir a segurança operacional. Neste contexto, este trabalho apresenta uma revisão dos principais fatores que interferem no processo de degradação do refratário $\mathrm{MgO}-\mathrm{C}$, o qual é o material mais amplamente utilizado nas linhas de escórias das panelas de aço do processo siderúrgico. Adicionalmente, algumas alternativas para reduzir ou inibir tal desgaste também são abordadas e discutidas.
\end{abstract}

Palavras-chave: refratário $\mathrm{MgO}-\mathrm{C}$, corrosão, oxidação, escória.

Abstract

Steel ladles are special vessels used for liquid steel transportation from the primary refining step up to its solidification at the casting shop. However, due to the increasing market demand for clean steel, new procedures have been implemented in the refining process resulting in more aggressive environments to the ladle refractory materials. In general, the upper region of the vessel, where the contact between slag and refractory takes place (known as slag line), is subjected to intense wearing and corrosion. This fact has significant implications, leading to a reduction steel ladle's availability at the steelshop, early refractory lining replacement repairs, production costs increase and reduction in safety. In this context, this work presents a review of the main factors involved in the degradation process of $\mathrm{MgO}-\mathrm{C}$ refractory, which is the most widely used material for slag lines in steelmaking. Additionally, some alternatives to reduce or inhibit such wearing are also discussed.

Keywords: $\mathrm{MgO}-\mathrm{C}$ refractory, corrosion, oxidation, slag.

\section{INTRODUÇÃO}

Ao longo dos últimos anos, a indústria de refratários vem se ajustando à nova realidade do setor siderúrgico visando principalmente desenvolver novos materiais que atendam as exigências inerentes à produção e refino de aço, além da redução de custos, racionalização de recursos e obtenção de produtos de elevada qualidade. Neste contexto siderúrgico, os refratários $\mathrm{MgO}-\mathrm{C}$ tem-se destacado devido às excelentes propriedades de resistência à corrosão, choque térmico, durabilidade e flexibilidade frente às atuais solicitações operacionais. Uma das principais aplicações deste material consiste no revestimento das panelas de aço que transportam metal líquido ao longo dos processos de refino nas aciarias. No entanto, devido à crescente demanda por aços de elevada qualidade e limpidez, os processos metalúrgicos vêm se tornando cada vez mais agressivos aos refratários, especialmente na região da linha de escória. Neste caso, os tijolos de $\mathrm{MgO}-\mathrm{C}$ podem tornarse fontes de inclusões indesejadas ao processo e por isso, a compreensão dos mecanismos de desgaste envolvidos nesta região são importantes para o desenvolvimento de novos materiais com superior desempenho. Assim, o projeto do revestimento e a seleção dos materiais são realizados por zoneamento, ou seja, baseando-se em regiões da panela que apresentam solicitações físicas e químicas semelhantes (Fig. 1). Este procedimento tem a função de garantir um melhor balanceamento do desgaste dos refratários, evitando que uma região tenha desgaste superior que outra, o que pode ocasionar paradas prematuras e indisponibilidade 
do equipamento [1, 2]. Portanto, os refratários não devem apresentar apenas elevada resistência química e física a altas temperaturas, mas também se manterem íntegros durante operação sob diversas condições operacionais [3]. Desta forma, para que ocorra a evolução tecnológica destes insumos faz-se necessário considerar os impactos não somente das matérias-primas utilizadas na etapa de fabricação (agregados de $\mathrm{MgO}$, carbono, ligantes e antioxidantes), mas também as condições operacionais (tais como basicidade, viscosidade, aquecimento, etc.) e de instalação do revestimento. Adicionalmente, modelamentos termodinâmicos e ensaios laboratoriais são algumas das ferramentas empregadas na avaliação dos mecanismos de desgaste e previsão de desempenho destes materiais. Assim, as próximas seções deste trabalho são dedicadas às principais características do refratário $\mathrm{MgO}-\mathrm{C}$ e dos mecanismos de desgaste envolvidos na linha de escória da panela de aço.

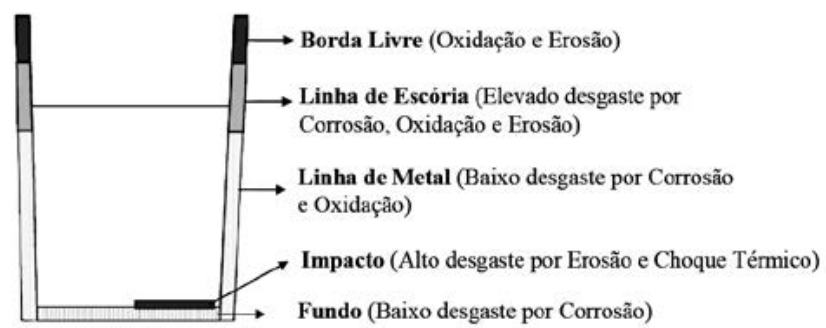

Figura 1: Zoneamento do revestimento da panela de aço em função das solicitações de desgaste (adaptado de [2]).

[Figure 1: Steel ladle lining zone regions as function of the wearing mechanisms (adapted from [2]).]

\section{Refratários MgO-C}

$\mathrm{O}$ refratário $\mathrm{MgO}-\mathrm{C}$ é considerado um material de alto desempenho devido às suas excelentes propriedades físico-químicas, sendo encontrado em quantidades e custo compatíveis com as necessidades dos processos metalúrgicos $[4,5]$. Sua primeira aplicação foi realizada entre 1975 e 1980 [6, 7] no Japão na forma de tijolos e a partir de então tornou-se referência na siderurgia em virtude de sua refratariedade, elevada condutividade térmica, excelente resistência térmica e ao choque térmico,

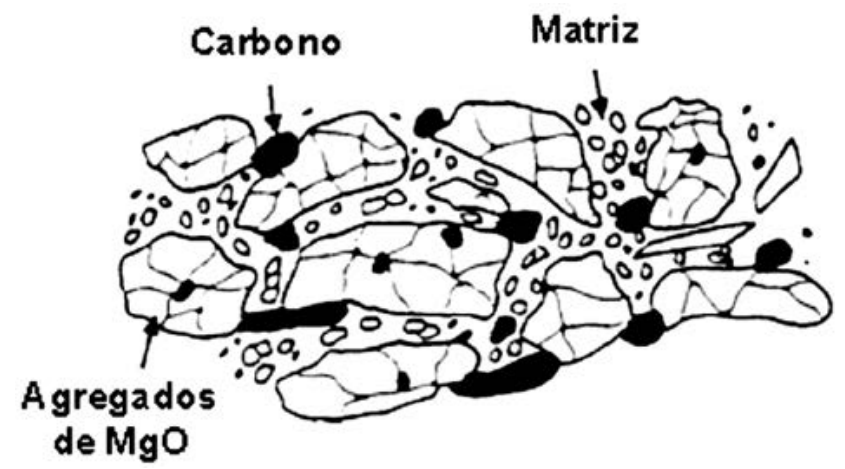

Figura 2: Ilustração esquemática da estrutura e constituintes dos refratários $\mathrm{MgO}-\mathrm{C}$ (adaptado de [13]).

[Figure 2: Schematic drawing of the $\mathrm{MgO}-\mathrm{C}$ refractory structure and components (adapted from [13]).] baixa molhabilidade por escória, alta absorção de tensões termomecânicas, etc. [7-10]. Tijolos de $\mathrm{MgO}-\mathrm{C}$ são fabricados utilizando-se as seguintes matérias-primas: agregados de magnésia (sinterizados ou eletrofundidos), grafita lamelar natural, ligante orgânico (alcatrão, piche ou resina fenólica) e aditivos metálicos [11, 12]. Na Fig. 2 tem-se uma ilustração esquemática da disposição dos componentes contidos neste tipo de refratário.

\section{Agregados de $\mathrm{MgO}$}

A magnésia ou óxido de magnésio $(\mathrm{MgO})$ é a matériaprima principal utilizada na fabricação de refratários básicos [14]. Ela pode ser obtida a partir da magnesita $\left(\mathrm{MgCO}_{3}\right)$ ou da água do mar (via $\mathrm{MgCl}_{2}$ ), sendo oferecidas no mercado na forma de grãos sinterizados ou eletrofundidos $[3,15]$. Os grãos eletrofundidos têm maior densidade, são praticamente isentos de porosidade inter e intragranular, possuem maiores cristais de periclásio e menor teor de impurezas, fato que resulta na redução das reações químicas deste material com a escória e, conseqüentemente, aumenta o desempenho do revestimento refratário [16-19]. Além disso, para o sistema $\mathrm{MgO}-\mathrm{C}$ a resistência à oxidação e à corrosão varia conforme a fonte de magnésia empregada nas composições dos tijolos: $\mathrm{MgO}$ natural < sínter de $\mathrm{MgO}$ $<\mathrm{MgO}$ eletrofundido [20, 21]. Os tamanhos de cristais de periclásio normalmente encontrados no mercado mundial variam entre 70 e $180 \mu \mathrm{m}$ para os agregados sinterizados, enquanto os eletrofundidos são da ordem de 450-950 $\mu \mathrm{m}$ [22]. Considerando que a corrosão de cristais de $\mathrm{MgO}$ inicia-se nas suas interfaces, tem-se que quanto menor o seu tamanho, maior será a área superficial e, por essa razão, estes apresentarão elevada reatividade ao longo do processo de dissociação e corrosão $[22,23]$. Este fato é comprovado pelos resultados de corrosão mostrados na Fig. 3, onde o impacto do tamanho dos grãos de $\mathrm{MgO}$ foi correlacionado com a taxa de desgaste do refratário.

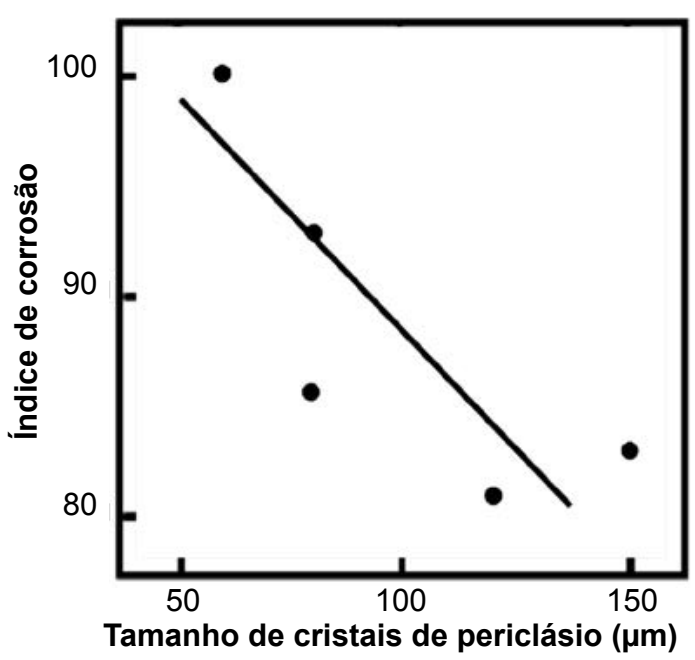

Figura 3: Efeito do tamanho de cristais de periclásio na taxa de corrosão do refratário MgO-C (adaptado de [24, 25]).

[Figure 3: Periclase crystal size effect on the $\mathrm{MgO}-\mathrm{C}$ refractory corrosion rate (adapted from [24, 25]).] 
A presença e distribuição de fases e/ou impurezas nos agregados de $\mathrm{MgO}$ também afeta enormemente as propriedades a quente das composições refratárias [26]. Observa-se na Fig. 4 que as impurezas (normalmente $\mathrm{CaO}$ e $\mathrm{SiO}_{2}$ ) tendem a se concentrar na região intergranular dos agregados. Assim, à elevada temperatura pode ocorrer a formação de uma fina camada de fase líquida que irá permear os grãos, influenciando a adesão destes com a estrutura. Caso a quantidade de líquido formada seja demasiada, o afastamento e até separação dos cristais poderá ocorrer, acarretando redução da resistência à corrosão do refratário $[19,27]$. Além disso, devido à maior concentração de defeitos da estrutura, como trincas, poros e maior contorno de grãos, este efeito descrito acima ainda torna-se mais acentuado nos agregados sinterizados $[17,28]$.

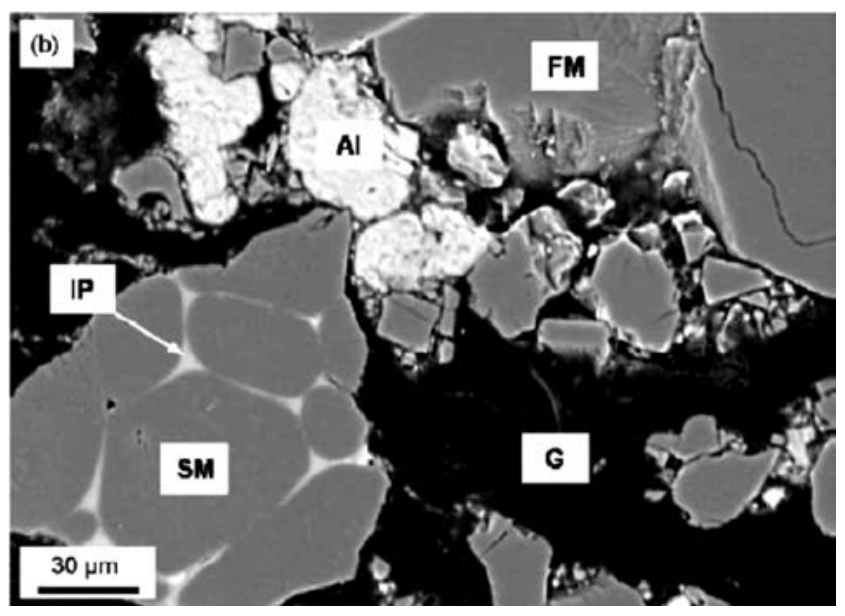

Figura 4: Distribuição de impurezas e outras fases nos agregados de $\mathrm{MgO}$ [29]. IP - impurezas, G - grafite, FM - MgO eletrofundido, $\mathrm{SM}$ - MgO sinterizado, Al - Alumínio metálico.

[Figure 4: Distribution of impurities and other phases in the $\mathrm{MgO}$ aggregates [29]. IP - impurities, G - graphite, FM - electrofused $\mathrm{MgO}, \mathrm{SM}$ - sintered $\mathrm{MgO}, \mathrm{Al}$ - metallic aluminium.]

Portanto, visando entender o comportamento dos tijolos $\mathrm{MgO}-\mathrm{C}$ frente as solicitações termomecânicas, torna-se imprescindível avaliar o efeito destes óxidos ou impurezas nas propriedades dos agregados. Landy [26] considera que em aplicações especiais os teores de $\mathrm{CaO}$ e $\mathrm{SiO}_{2}$ contido nos agregados de $\mathrm{MgO}$ devem ser menores que 2,5\%, enquanto para aplicações em panelas de aço este valor é ainda mais reduzido $(<1 \%)$, uma vez que quanto menor a pureza dos

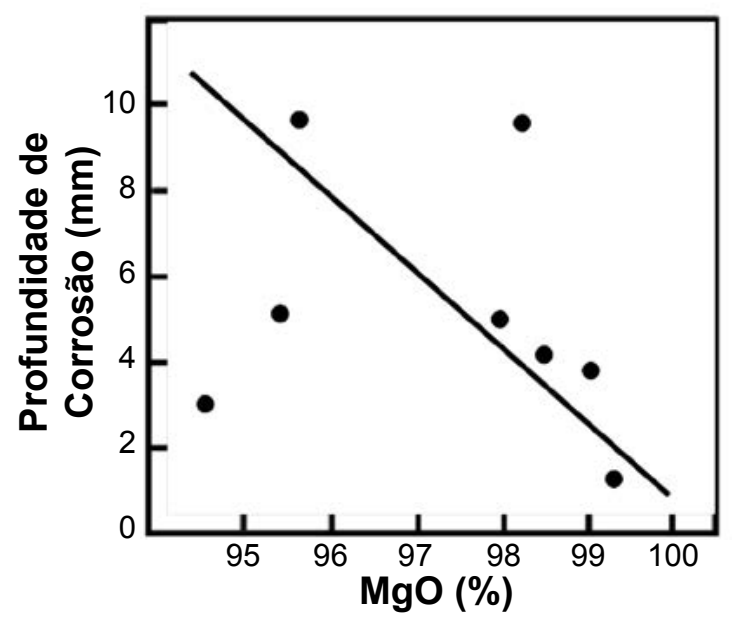

Figura 5: Efeito da pureza dos agregados de $\mathrm{MgO}$ na taxa de corrosão de um refratário (adaptado de [24, 25]).

[Figure 5: Effect of $\mathrm{MgO}$ aggregates purity on the refractory corrosion rate (adapted from [24, 25]).]

agregados maior a taxa de corrosão do refratário (como mostrado na Fig. 5).

No sistema $\mathrm{MgO}-\mathrm{CaO}-\mathrm{SiO}_{2}$ a temperatura de formação de fase líquida e a natureza dos minerais gerados é função da razão $\mathrm{CaO} / \mathrm{SiO}_{2}$. Ou seja, por meio da basicidade dos agregados podem ser previstas as fases que estarão presentes em condições de equilíbrio termodinâmico (Tabela I). Quando a razão $\mathrm{CaO} / \mathrm{SiO}_{2}$ é inferior a 2, as composições estarão situadas na região onde se encontram os eutéticos de menores temperaturas no sistema $\mathrm{MgO}-\mathrm{CaO}-\mathrm{SiO}_{2}$ (entre 1320 e $1387{ }^{\circ} \mathrm{C}$ ), podendo haver a formação das fases monticelita (CMS), mervinita $\left(\mathrm{C}_{3} \mathrm{MS}_{2}\right)$ e forsterita $\left(\mathrm{M}_{2} \mathrm{~S}\right)$. Por outro lado, razões superiores a 2 resultam na presença de reações eutéticas somente a temperaturas mais elevadas (1790- $\left.1850^{\circ} \mathrm{C}\right)$, devido a presença de compostos refratários como os silicatos di- e tricálcio. Portanto, tem-se que quanto maior a razão $\mathrm{CaO} / \mathrm{SiO}_{2}$ maior será a temperatura de início de formação de líquido [30]. Adicionalmente, o aumento do teor de $\mathrm{CaO}$ nos agregados de $\mathrm{MgO}$ prejudica o desempenho químico dos tijolos refratários quando em contato com escórias contendo alta concentração de óxidos de ferro, havendo posteriormente a formação de fases com reduzido ponto de fusão (próximas a $1160^{\circ} \mathrm{C}$ ) $[15,30]$. Outra importante impureza que pode estar presente nos agregados de $\mathrm{MgO}$ é o óxido de boro, $\mathrm{B}_{2} \mathrm{O}_{3}$ Quando contido nestes

Tabela I - Fases formadas em relação à basicidade das impurezas presentes nos agregados de $\operatorname{MgO}[15,30]$.

[Table I - Phases that can be formed as a function of the basicity of the impurities contained in the MgO aggregates [15, 30].]

\begin{tabular}{|c|c|c|c|c|c|c|}
\hline \multicolumn{7}{|c|}{$\mathrm{CaO} / \mathrm{SiO}_{2}$} \\
\hline Basicidade & $0,0-1,0$ & $1,0-1,5$ & $1,5-2,0$ & & $>2,0$ & \\
\hline & $\mathrm{MgO}$ & $\mathrm{MgO}$ & $\mathrm{MgO}$ & $\mathrm{MgO}$ & $\mathrm{MgO}$ & $\mathrm{MgO}$ \\
\hline Fases & Espinélio & Espinélio & Espinélio & Espinélio & $\mathrm{C}_{2} \mathrm{~S}$ & $\mathrm{CaO}$ \\
\hline formadas & M,S & CMS & $\mathrm{C}_{3} \mathrm{MS}_{2}$ & $\mathrm{C}_{2} \mathrm{~S}$ & $\mathrm{C}_{3}^{2} \mathrm{~S}$ & $\mathrm{C}_{3} \mathrm{~S}$ \\
\hline & $\mathrm{CMS}^{2}$ & $\mathrm{C}_{3} \mathrm{MS}_{2}$ & $\mathrm{C}_{2} \mathrm{~S}^{2}$ & $\mathrm{C}_{2}^{2} \mathrm{~F}$ & $\mathrm{C}_{2}^{3} \mathrm{~F}$ & $\mathrm{C}_{2}^{3} \mathrm{~F}$ \\
\hline
\end{tabular}

$M_{2} S=$ forsterita, $C M S=$ monticelita, $C_{3} M S_{2}=$ mervinita, $C_{2} S=$ silicato de cálcio, $C_{3} S=$ silicato tricálcio, $C_{2} F=$ ferrita de cálcio. 
materiais mesmo em concentrações de alguns décimos porcentuais em peso $(>0,02 \%)$, este componente poderá resultar na queda da refratariedade sob carga a temperaturas relativamente baixas $\left(1200-1250{ }^{\circ} \mathrm{C}\right)$ e aumentar a taxa de corrosão do refratário, em virtude da formação de fase líquida em sua estrutura. Cabe ressaltar, no entanto, que esta impureza é mais predominantemente encontrada em sínter de magnésia de água do mar [31,32].

Em resumo, visando a obtenção de uma composição do sistema $\mathrm{MgO}-\mathrm{C}$ com elevada refratariedade e resistência à corrosão, torna-se desejável o emprego de agregados de $\mathrm{MgO}$ com tamanho de cristal grande, maior quantidade de grãos eletrofundidos, baixo teor de impurezas, razão $\mathrm{CaO}$ / $\mathrm{SiO}_{2}$ alta e baixo teor de $\mathrm{B}_{2} \mathrm{O}_{3}[28,33]$.

\section{Carbono}

Nas suas variadas formas, o carbono é um dos mais importantes constituintes dos refratários modernos utilizados na siderurgia, podendo geralmente ser encontrado em composições contendo alumina, zircônia e magnésia $[34,35]$. As principais razões para o uso de carbono em refratários siderúrgicos são [34]: alta refratariedade e estabilidade térmica em condições não-oxidantes; baixa molhabilidade por líquidos polares, em particular escórias de silicatos; alta condutividade térmica; aumento da resistência ao choque térmico, pelo aumento da energia de fratura e pela alta condutividade térmica; facilidade de impregnação em estruturas porosas, sendo considerado um bom ligante de fases.

As fontes de carbono utilizadas nos refratários de $\mathrm{MgO}-\mathrm{C}$ geralmente variam de 5 a $15 \%$ em peso, sendo empregadas na forma de sólidos (grafite, negro de fumo) ou como ligante (piche e resina polimérica) [36, 37]. Em ambos os casos, o carbono adicionado substituirá principalmente a fração fina de magnésia, a fim de manter a densidade de empacotamento do refratário [38, 39]. Em síntese, comprova-se que: (a) o grafite é o responsável por aumentar a resistência ao ataque por escória e ao choque térmico; (b) o piche pode ser usado como ligante de fases ou como agente de impregnação para preencher poros; (c) as resinas são comumente utilizadas como ligantes; e (d) o negro de fumo é considerado como um material de preenchimento [11,34]. Nos tijolos de $\mathrm{MgO}-\mathrm{C}$, o grafite e a resina são as principais fontes de adição de carbono.

\section{Grafite}

O grafite apresenta estrutura cristalina lamelar, conforme apresentado na Fig. 6. Esta estrutura confere características anisotrópicas a este material, uma vez que as propriedades ao longo da camada planar são distintas daquelas obtidas na região basal. Dentre os benefícios decorrentes desta estrutura está o fato de o plano basal do grafite possuir baixa energia superficial e, considerando também que as ligações entre os átomos são predominantemente covalentes, obtêm-se assim um material que apresenta baixa molhabilidade por líquidos polares (p.ex., escórias siderúrgicas) [40, 41]. Contudo, foi mostrado que em refratários do tipo $\mathrm{MgO}-\mathrm{C}$ existe um teor mínimo de $5 \%$ de carbono na composição a partir do qual afeta significativamente a redução na molhabilidade [34].

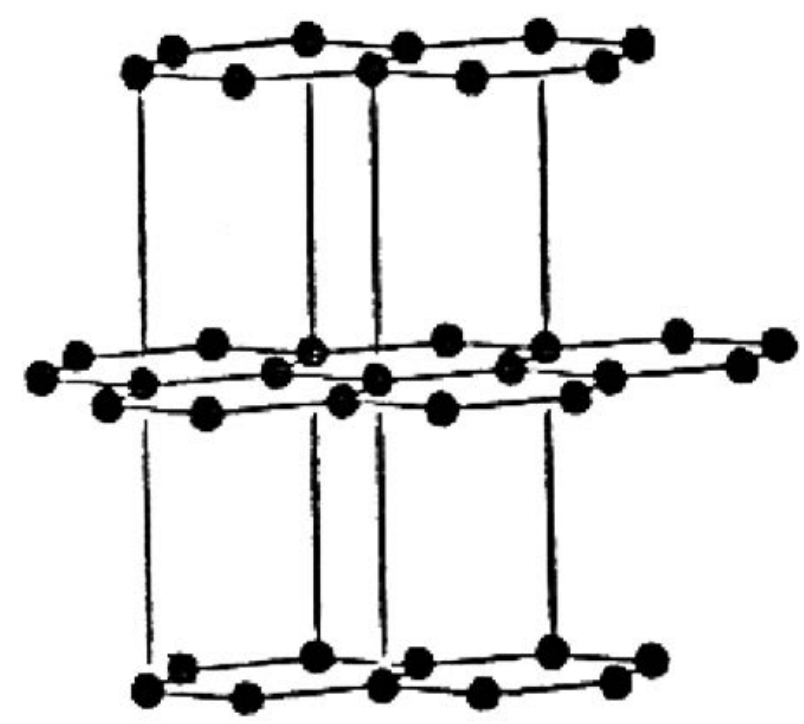

Figura 6: Estrutura cristalina do grafite [42].

[Figure 6: Crystal structure of graphite [42].]

Outra vantagem inerente a esta estrutura lamelar é a sua elevada flexibilidade [5], permitindo que ocorra a deformação plástica das lamelas durante a fabricação dos tijolos, alinhando-as perpendicularmente ao eixo de prensagem sem que ocorra a fratura do material. Esta capacidade também confere melhor preenchimento dos espaços entre os agregados, promovendo menor porosidade e melhor compactação da estrutura final $[40,41]$. As reações de oxidação do grafite ocorrem nas extremidades dos cristais ou lamelas. Neste contexto, quanto maior o tamanho

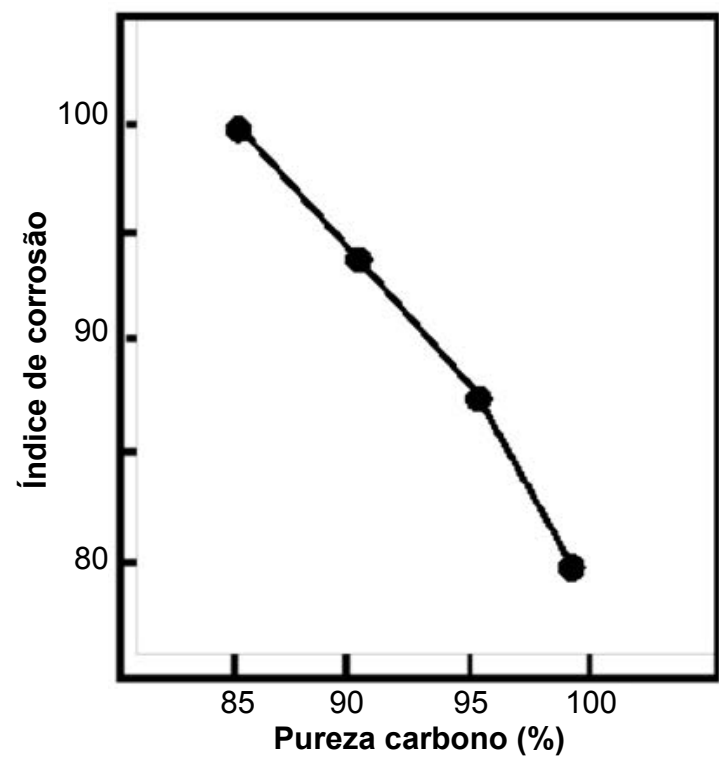

Figura 7: Efeito da pureza do grafite em relação a taxa de corrosão de refratários $\mathrm{MgO}-\mathrm{C}[25,45]$.

[Figure 7: Effect of graphite purity on the $\mathrm{MgO}-\mathrm{C}$ refractory corrosion rate [25, 45].] 
das lamelas e sua pureza, menor é a taxa de oxidação do grafite e maior a resistência à corrosão do refratário [43]. As cinzas ou impurezas contidas no grafite (comumente constituídas por quartzo, mica, muscovita, pirita, óxido de ferro, feldspatos, etc.) encontram-se interligadas às lamelas e não podem ser separadas sem comprometer a estrutura deste material. Quanto maior o teor de impurezas das cinzas, maior a quantidade de fase líquida formada no refratário, reduzindo a resistência física e química do mesmo (Fig. 7). Adicionalmente, as impurezas tendem a se manter na estrutura mesmo após a decomposição do carbono, aumentando a possibilidade de uma posterior reação com os agregados de $\mathrm{MgO}$ e formação de fases de baixo ponto de fusão [44].

\section{Ligantes contendo carbono}

Ligantes são aglutinantes que atuam na coesão entre agregados e matriz, possibilitando a conformação via prensagem e permitindo o manuseio e instalação do tijolo nos equipamentos [26, 46]. O piche verde e as resinas poliméricas são tradicionalmente os ligantes mais utilizados em refratários de $\mathrm{MgO}-\mathrm{C}$ devido à facilidade de uso e mistura, capacidade de adesão com agregados e finos, além de baixo riscos à saúde e ao meio ambiente [47-49]. Adicionalmente, os ligantes representam de 3,5 a 5,0\% da composição dos refratários, sendo que durante a etapa de aquecimento sofrem reações irreversíveis por meio do processo de carbonização, resultando na formação de carbono residual (ou fixo) entre os agregados. A quantidade de carbono gerado após queima contribui para o aumento da adesão da estrutura e melhoria na resistência química do refratário. Sendo assim, normalmente procura-se utilizar fontes que resultam em alto valor de carbono fixo [48]. Desta forma, torna-se desejável que a reatividade do carbono do ligante seja a menor possível, sendo esta característica altamente influenciada pela orientação do mesmo. Em geral, quanto maior o grau de orientação (grafitização) menor as reações envolvendo o carbono e, conseqüentemente, maior será a sua resistência à oxidação $[42,50]$. Teoricamente, o carbono proveniente dos ligantes somente apresentará a estrutura planar do grafite após tratamentos térmicos acima de $2500{ }^{\circ} \mathrm{C}$. Em temperaturas inferiores os seguintes arranjos podem ser obtidos: (1) carbono grafitizável, o qual possui estrutura planar orientada similar a do grafite natural; (2) carbono não-grafitizável, apresentando unidades orientadas aleatoriamente e que são difíceis de serem cristalizadas; e (3) carbono amorfo, que não apresenta nenhuma linearidade e orientação, sendo este o material com maior reatividade e probabilidade de sofrer oxidação quando em presença de oxigênio [42,51]. O piche é caracterizado como um termoplástico de baixo custo que possui grande afinidade por materiais inorgânicos como o $\mathrm{MgO}$ e que tem sua origem na decomposição térmica de compostos orgânicos provenientes, principalmente, de alcatrão de carvão e petróleo [34, 36, 51]. Este apresenta carbono residual grafitizável, o que promove a formação e orientação de longas cadeias, sendo estas responsáveis pelas características anisotrópicas desenvolvidas por este material após queima e que contribuem para aumentar resistência à corrosão [51-53]. Este fenômeno é decorrente da carbonização da estrutura grafítica ainda no estado de mesofase, que consiste em hidrocarbonetos aromáticos alinhados paralelamente. No entanto, esta fonte de carbono somente tem transformação efetiva em temperatura acima de $2000{ }^{\circ} \mathrm{C}$, superior ao praticado na siderurgia $[47,49,51]$. $\mathrm{O}$ piche ainda apresenta composição química heterogênea e sua utilização na fabricação de refratários deve ser efetuada em temperaturas na faixa de 100 a $200{ }^{\circ} \mathrm{C}$, para que o mesmo atinja fluidez adequada para a mistura e o processamento. Todavia, a grande desvantagem deste ligante é referente à elevada emissão de voláteis tóxicos e cancerígenos, que ocorrem na pirólise do mesmo. Para reduzir os aspectos negativos desta substância tem sido desenvolvidos materiais com reduzido impacto ambiental como o piche derivado de petróleo e de produtos conhecidos como Carbores ${ }^{\circledR} \mathrm{P}$ (a partir do carvão mineral).

Já as resinas fenólicas são polímeros termofixos que apresentam boa trabalhabilidade durante processamento e alto teor de carbono fixo após queima, sendo este encontrado no estado amorfo e com estrutura isotrópica [54-56]. O carbono amorfo resultante deste ligante possui tal característica em virtude do arranjo polimérico que lhe deu origem e de sua elevada área superficial, ocasionando orientação curta das cadeias e impedindo a grafitização propriamente dita. Além disso, o controle e até mesmo aumento do carbono residual deste material pode ser obtido por meio da seleção de resinas em relação à densidade das ligações cruzadas formadas após cura ou por processos adicionais de cloração e pré-oxidação $[42,51]$. Uma importante vantagem da resina fenólica é que ela permite mistura e processamento a frio dos materiais refratários que as contem, o que reduz custos de operação e com equipamentos [35]. Na Tabela II são sumarizadas as principais propriedades da resina e piche utilizados em refratários.

Tabela II - Propriedades dos ligantes piche e resina [55]. [Table II - Properties of pitch and resin binders [55].]

\begin{tabular}{lcc}
\hline Ligantes & Piche & Resina \\
\hline Voláteis tóxicos, ppm & $10.000-15.000$ & 0 \\
Estrutura do Carbono & anissotrópica & isotrópia \\
Carbono Residual, \% & $50-60$ & $40-50$ \\
Impurezas, \% & $<0,4$ & 0 \\
Ponto de amolecimento, ${ }^{\circ} \mathrm{C}$ & 97 & - \\
Processo de Mistura & á quente & Temp. ambiente \\
\hline
\end{tabular}

Atualmente, na fabricação de refratários do sistema MgO-C utiliza-se uma combinação de piche e resina, visando obter a otimização das propriedades do tijolo conforme as necessidades dos clientes e dos equipamentos onde estes materiais serão aplicados [57]. Todavia, novos estudos [58] avaliaram a adição de catalisadores em resinas que resultam na redução da temperatura de grafitização do carbono residual para aquelas próximas às encontradas no 
aquecimento e operação dos refratários. Resultados parciais indicam similaridade de propriedades entre estas resinas e o grafite natural, indicando seu grande potencial para uso em siderurgia e até na substituição total do piche.

Solicitações a que os refratários de $\mathrm{MgO}-\mathrm{C}$ são submetidos durante a operação de panelas de aço

As panelas de aço são recipientes que transportam o aço líquido ao longo das etapas de produção na aciaria, desde o vazamento do refino primário até o lingotamento. Neste processo, o revestimento destes equipamentos (normalmente constituído por tijolos de $\mathrm{MgO}-\mathrm{C}$ ) é exposto a solicitações diversas de origens térmicas, mecânicas e químicas (Fig. 8), as quais têm forte influência no desempenho final dos refratários. Considerando os refratários utilizados na linha de escória, existe a predominância dos desgastes químicos, que envolvem a oxidação do carbono e a corrosão dos agregados de $\mathrm{MgO}$ pela escória, os quais serão abordados em detalhes nas próximas seções [20].

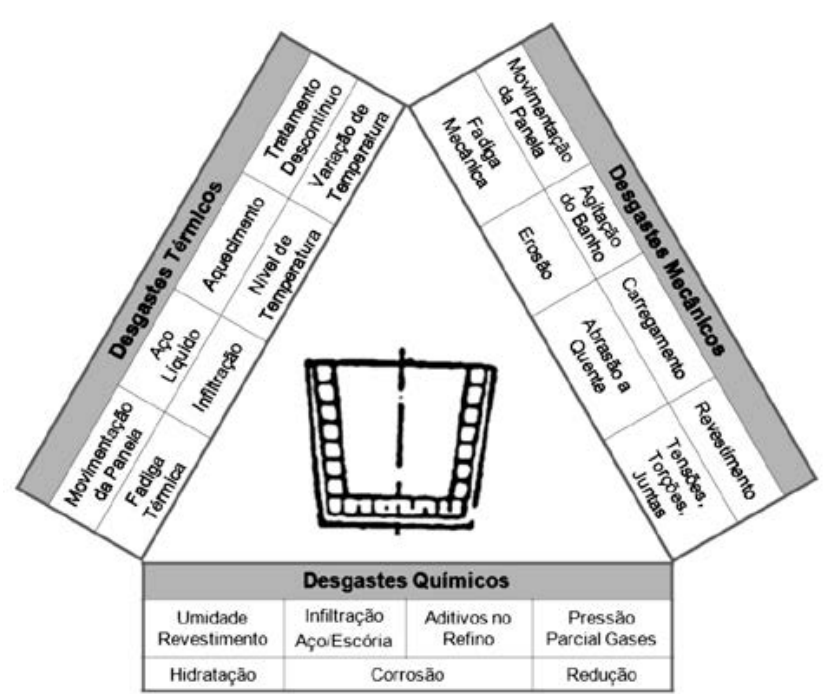

Figura 8: Mecanismos de desgaste de refratários para panelas de aço (adaptado de [59]).

[Figure 8: Wearing mechanisms of steel ladle refractories (adapted from [59]).]

\section{Oxidação}

A oxidação dos refratários $\mathrm{MgO}-\mathrm{C}$ acarreta na degradação das propriedades destes materiais, uma vez que gera o aumento da porosidade e deterioração da ligação entre os seus constituintes. Assim, durante a operação de uma panela de aço onde existe o contato de escórias fundidas com o revestimento, uma penetração mais acentuada deste líquido e posterior reação com os agregados de $\mathrm{MgO}$ podem provocar a dissolução e dissociação destes componentes [60, 61]. Portanto, a durabilidade dos refratários contendo carbono, sob condições operacionais em presença de oxigênio, dependerá diretamente da eficiência no controle ou retardamento da oxidação [62,63]. O mecanismo de oxidação é classificado em duas categorias: direta e indireta. A primeira ocorre por via gasosa em temperaturas entre 600 e $700{ }^{\circ} \mathrm{C}$, uma vez que o carbono é consumido pelo oxigênio (Eq. A).

$$
2 \mathrm{C}_{(\mathrm{s})}+\mathrm{O}_{2(\mathrm{~g})} \leftrightarrow 2 \mathrm{CO}_{(\mathrm{g})}
$$

Já a segunda ocorre acima desta temperatura com precipitação secundária de magnésia a partir da oxidação do gás $\mathrm{Mg}_{\mathrm{g})}$ na superfície do refratário, resultante da interação do carbono com o oxigênio proveniente do $\mathrm{MgO}$ sólido (Eqs. B e C).

$$
\begin{aligned}
& \mathrm{C}_{(\mathrm{s})}+\mathrm{MgO}_{(\mathrm{s})} \leftrightarrow \mathrm{CO}_{(\mathrm{g})}+\mathrm{Mg}_{(\mathrm{g})} \\
& \mathrm{Mg}_{(\mathrm{g})}+1 / 2 \mathrm{O}_{2(\mathrm{~g})} \leftrightarrow \mathrm{MgO}_{(\mathrm{s})}
\end{aligned}
$$

Neste último processo tem-se o desenvolvimento da chamada camada densa de $\mathrm{MgO}$ (ilustrada na Fig. 9) que atua como barreira a entrada e difusão de oxigênio e a saída de monóxido de carbono para o exterior do refratário, promovendo o equilíbrio das pressões parciais dos gases no sistema. Assim, esta proteção contribui para aumentar a resistência química por meio da redução da porosidade e do desgaste, resultando na melhoria da durabilidade do tijolo $[32,64]$. A oxidação também pode ocorrer na face fria do revestimento. Este efeito está associado a uma combinação de temperaturas relativamente baixas durante o início de operação do revestimento e de flutuações de temperatura ao longo da campanha [66].

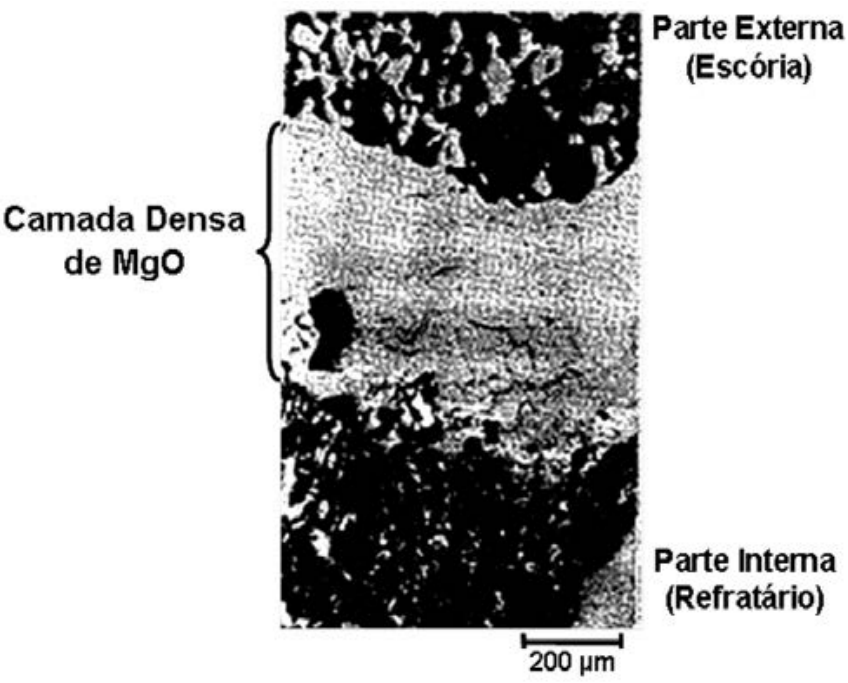

Figura 9: Camada densa de $\mathrm{MgO}$ formado na superfície dos refratários de $\mathrm{MgO}-\mathrm{C}$ (adaptado de [65]).

[Figure 9: $\mathrm{MgO}$ dense layer formed at the $\mathrm{MgO}-\mathrm{C}$ refractory surface (adapted from [65]).]

Outra forma possível de oxidação do refratário de $\mathrm{MgO}-\mathrm{C}$ é via fase líquida, onde algumas reações com os componentes da escória, como por exemplo óxidos de ferro e manganês (Eq. D e E) podem promover o consumo de carbono e a formação de gases juntamente com o monóxido de carbono.

$$
\mathrm{C}_{(\mathrm{s})}+\mathrm{Fe}_{\mathrm{x}} \mathrm{O}_{(\mathrm{l})} \leftrightarrow \mathrm{xFe}_{(\mathrm{g}, \mathrm{l})}+\mathrm{CO}_{(\mathrm{g})}
$$




$$
\mathrm{C}_{(\mathrm{s})}+\mathrm{MnO}_{(\mathrm{l})} \leftrightarrow \mathrm{Mn}_{(\mathrm{g}, \mathrm{l})}+\mathrm{CO}_{(\mathrm{g})}
$$

Aquecimento do revestimento das panelas de aço

Geralmente os refratários de $\mathrm{MgO}-\mathrm{C}$ para linha de escória em panelas de aço são fornecidos na forma de tijolos pré-queimados. Entretanto, durante o primeiro aquecimento dos refratários que revestem estes equipamentos (entre 10 e $36 \mathrm{~h}$ antes do início de operação) tem-se as reações de carbonização dos ligantes e oxidação do carbono, que são acompanhadas pela emissão de voláteis em diferentes temperaturas de acordo com o aditivo empregado na composição refratária [67]. Por exemplo, na Fig. 10 observase as faixas destas duas transformações químicas, sendo constatado a maior resistência térmica do piche em relação à resina e do grafite natural quando comparado ao carbono amorfo.

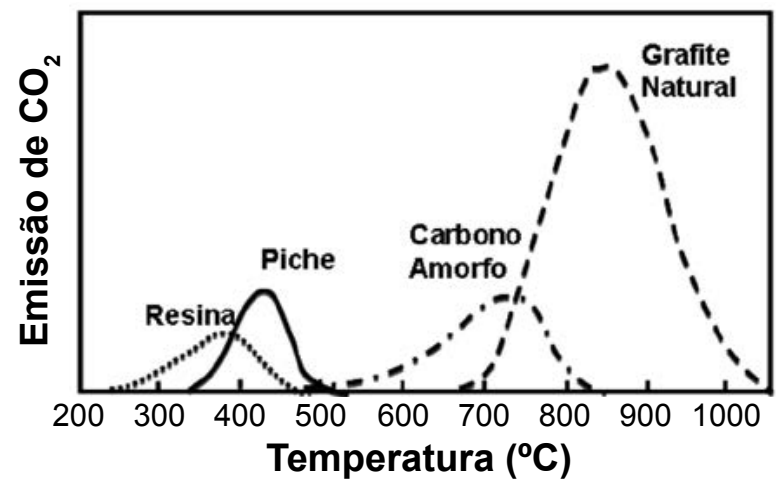

Figura 10: Carbonização dos ligantes e oxidação do carbono em função da temperatura (adaptado de [59]).

[Figure 10: Binder carbonization and carbon oxidation as a function of the temperature (adapted from [59]).]

Ligantes com baixo teor de carbono fixo após carbonização promovem aumento na porosidade da estrutura do refratário, uma vez que os locais ocupados pelas partículas darão origem a novos vazios [67]. Geralmente, tijolos a base de piche tem menor porosidade, quando comparado com aquele contendo resina, conforme apresentado na Fig. 11.

Adicionalmente, a dimensão do refratário também tem impacto nesta propriedade, pois em tijolos grandes a taxa de geração de gases é baixa, aumentando a concentração de carbono disponível para reação em altas temperaturas [51]. No entanto, foi comprovado que o grau de oxidação pode ser reduzido a partir do controle das taxas de aquecimento, auxiliando na obtenção de menor volume de poros e, conseqüentemente, ampliando a resistência física e química do refratário [68]. Por isso, cuidados especiais na prática de aquecimento do revestimento são importantes para manter a integridade do mesmo. Os aquecedores industriais operam com mistura de combustível e oxigênio, sendo possível variar a proporção dos constituintes para equalizar a temperatura necessária e custo de operação. $\mathrm{O}$ aumento na injeção de oxigênio e o pré-aquecimento do ar promovem maior poder calorífero das chamas e menor gradiente térmico no revestimento [69]. Todavia, a injeção de oxigênio deve ser controlada, pois esta favorece a oxidação de carbono [70].
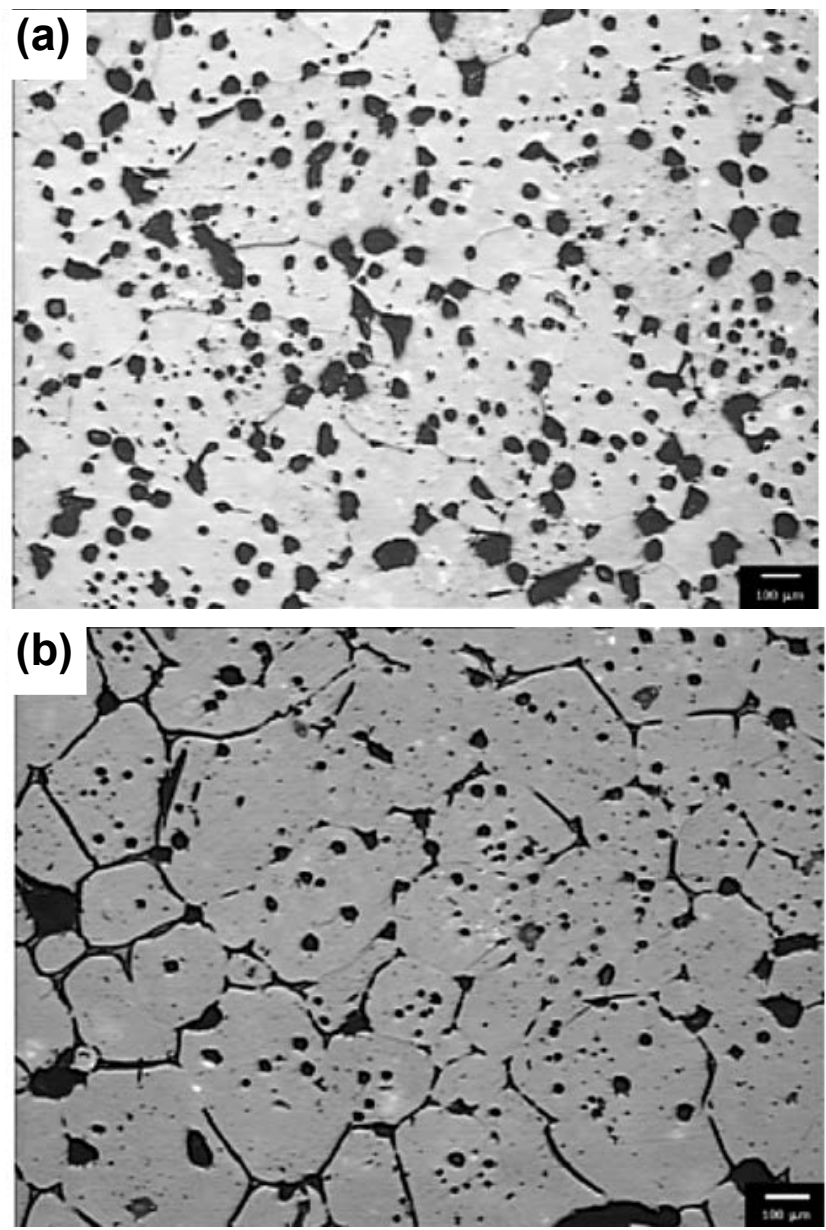

Figura 11: Refratário a base de (a) resina e (b) piche [54]. [Figure 11: (a) Resin and (b) pitch based refractories [54].]

Neste contexto, estudos indicaram que a velocidade de aquecimento é inversamente proporcional a taxa de oxidação (Fig. 12), de forma que para maiores taxas de aquecimento haverá menor oxidação dos tijolos de $\mathrm{MgO}-\mathrm{C}[68,37]$.

Embora seja recomendado utilizar elevadas taxas de aquecimento, outro ponto importante e que merece atenção

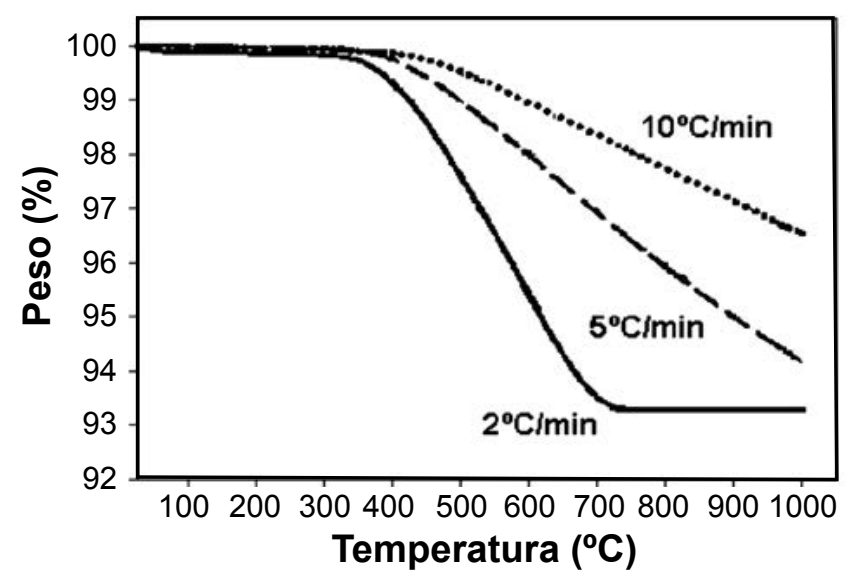

Figura 12: Efeito das taxas de aquecimento sobre grau de oxidação dos refratários MgO-C [37].

[Figure 12: Heating rate effect on the $\mathrm{MgO}-\mathrm{C}$ refractories oxidation rate [37].] 
consiste no balanceamento do aquecimento e da taxa de remoção de voláteis do refratário, de forma a evitar riscos à segurança operacional. Por exemplo, caso as taxas de aquecimento sejam altas na faixa de temperatura de vaporização dos ligantes, a emissão acentuada de gases pode gerar elevada pressão interna na estrutura do refratário e aumentar a possibilidade de ocorrência de explosões. Assim, foi destacado que durante a fase inicial de pré-aquecimento torna-se necessário operar com baixas taxas de aquecimento, fato que também auxilia na redução do volume de poros [71]. Durante o aquecimento altas tensões de compressão ocorrem no revestimento em decorrência da expansão dos tijolos que estão engastados entre si [72]. De acordo com a Fig. 13, observa-se que dependendo dos formatos dos tijolos pode ocorrer a formação de trincas verticais e horizontais na face quente do revestimento, sendo este um importante mecanismo de desgaste para os tijolos $\mathrm{MgO}-\mathrm{C}$ [66]. Com isso, deve-se visar o aquecimento rápido, no entanto sem induzir tensões por choque térmico, para evitar falhas prematuras no revestimento [73, 74].
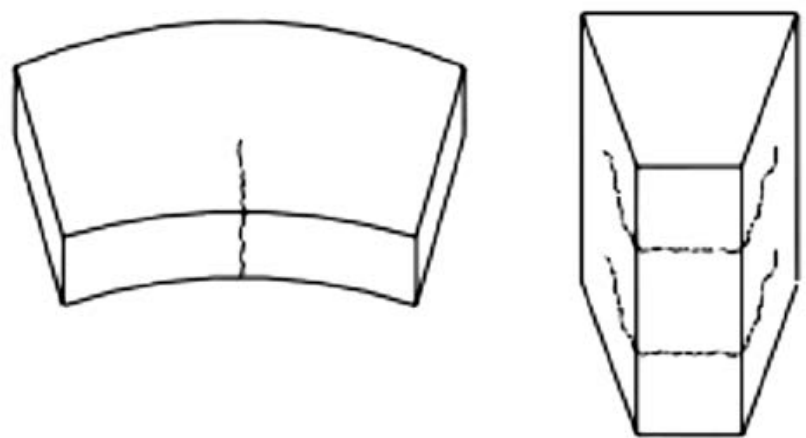

Figura 13: Trincamento típico por choque térmico em diferentes formatos de tijolos refratários $\mathrm{MgO}-\mathrm{C}[6]$.

[Figure 13: Typical thermal shock cracking in $\mathrm{MgO}-\mathrm{C}$ refractory bricks with different shapes [6].]

Outro ponto de observação é a flutuação térmica ao longo do ciclo produtivo. Simulações efetivadas por Hanifi [72] demonstraram o impacto negativo do aumento das oscilações térmicas e variações nas tensões geradas no revestimento das panelas de aço. Conforme mencionado anteriormente, uma das formas de reduzir a oxidação é a formação da camada densa de $\mathrm{MgO}$ na superfície do refratário. Todavia durante o primeiro aquecimento dos tijolos não existe condições de temperatura e tempo suficientes para iniciar a geração da mesma. Com isso, não é factível considerar este mecanismo de proteção para panelas durante a etapa de aquecimento [68].

\section{Corrosão}

A corrosão é caracterizada pelo desgaste por um líquido de elevado potencial químico (corrosivo, p.e. escória), de forma que os produtos da reação tendem ao equilíbrio termodinâmico na região de interface sólido-líquido [75]. Assim, nas aciarias, a corrosão na panela de aço pode ser descrita como a condição de equilíbrio entre as fases sólidas do refratário e fase líquida da escória [76]. A escória é um componente fundamental na fabricação do aço, sendo ela a responsável pela proteção contra oxidação e remoção de inclusões, ajudando a melhorar a qualidade do produto final. No entanto, as escórias ainda são consideradas o principal agente corrosivo do refratário nos processos siderúrgicos, pois estas aceleram o desgaste do revestimento contido nos equipamentos, gerando também a introdução de inclusões óxidas e não-metálicas no aço líquido [40, 77]. A taxa de corrosão é dada pelo gradiente de potencial químico (diferenças entre as composições química do sólido e líquido), sendo esta influenciada pela temperatura, composição na interface refratário/escória, densidade, viscosidade e difusividade dos reagentes [16]. Com isso, as reações químicas prosseguem até que se atinja a saturação dos constituintes do refratário na escória [78]. No caso do refratário do sistema $\mathrm{MgO}-\mathrm{C}$, escórias com baixo teor de $\mathrm{MgO}$ são as mais agressivas, podendo incorporar facilmente este óxido em sua composição até ser atingido o estado de saturação [17, 79]. No entanto, Liu et al [80] afirmaram que uma das formas de retardar este ataque corrosivo ao refratário consiste na adição de $\mathrm{MgO}$ na escória para aumentar a viscosidade e acelerar saturação da mesma. Assim, o revestimento ideal seria aquele que possui baixa dissolução pela escória ou que permita a rápida saturação do líquido pelos constituintes do refratário [23]. A corrosão pode ser considerada ativa, quando se tem solubilidade ou dissociação direta do refratário na escória, ou passiva, no caso da taxa de desgaste ser dependente da precipitação e dissolução de novas fases na interface sólido-líquido. No último caso, tem-se um efeito positivo, pois as fases formadas tendem a atuar como uma barreira, evitando a penetração do líquido e a continuidade da corrosão (como por exemplo, no caso da formação da camada densa de $\mathrm{MgO}$ ). Adicionalmente, o ataque químico se inicia pelos componentes com maior solubilidade, ou seja, com maior potencial termodinâmico para dissolução. Assim, a utilização de agregados maiores na estrutura garante maior resistência à corrosão do refratário, uma vez que partículas pequenas com baixo raio de curvatura e formatos angulares têm maior área superficial e são mais reativas. [13, 80]. Em termos operacionais, o desempenho do refratário depende dos tratamentos metalúrgicos e ritmo de produção das aciarias [2, 45], sendo que dentre os principais parâmetros de processo destacam-se a basicidade, a viscosidade e a concentração dos óxidos de ferro.

\section{Basicidade}

A razão $\mathrm{CaO} / \mathrm{SiO}_{2}$ da escória exerce considerável influência no desgaste do revestimento refratário das panelas, fato que pode ser comprovado pela influência deste parâmetro na solubilidade de $\mathrm{MgO}$ (Fig. 14). O desgaste químico aumenta linearmente com a temperatura e de forma não-linear com a redução da basicidade [81].

Similarmente às informações apresentadas na seção Agregados de $\mathrm{MgO}$, para razões menores que 2 forma-se fases de menor refratariedade entre escória e refratário, as 


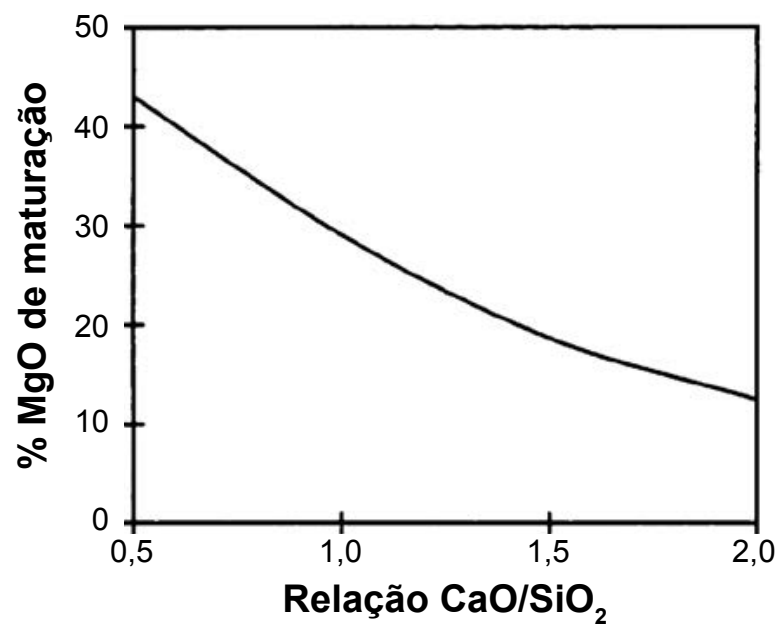

Figura 14: Efeito da relação $\mathrm{CaO} / \mathrm{SiO}_{2}$ (basicidade) sobre a solubilidade de $\mathrm{MgO}$ do refratário [31].

[Figure 14: Effect of $\mathrm{CaO} / \mathrm{SiO}_{2}$ ratio (basicity) on the $\mathrm{MgO}$ solubility of the refractory [31].]

quais são facilmente incorporadas pelo líquido em altas temperaturas. Adicionalmente, a baixa basicidade reduz a viscosidade e tensão superficial da escória, intensificando a separação e dissolução de partículas pela facilidade de penetração na estrutura dos agregados. [24, 31]. Por outro lado, a razão $\mathrm{CaO} / \mathrm{SiO}_{2}$ ainda pode auxiliar a manter o balanceamento entre a formação e dissolução da camada densa de $\mathrm{MgO}$ na superfície do refratário [32]. Portanto, um líquido com elevada basicidade poderá promover uma taxa de corrosão mais lenta quando comparado com as reações de deposição de magnésia secundária na superfície do material, favorecendo assim o desempenho do revestimento em altas temperaturas.

\section{Viscosidade}

A viscosidade da escória afeta diretamente a capacidade de dissolução e de infiltração da fase líquida na estrutura dos refratários e, conseqüentemente, ela pode aumentar ou reduzir a taxa de corrosão destes materiais [75, 32]. Esta propriedade varia, principalmente, de acordo com a temperatura e a concentração de formadores e modificadores de rede (ou fundentes) presentes na fase líquida. Como regra geral, o aumento da temperatura promove a redução da viscosidade do líquido. Assim, uma vez que durante o uso se estabelece um gradiente de temperatura entre a face quente e fria do refratário, o processo de infiltração pode ser inibido pelo aumento da viscosidade ao longo da espessura do revestimento [13]. Além disso, vale ressaltar que, caso a dissolução do refratário promova o aumento da viscosidade da escória, o processo corrosivo deverá ser minimizado devido à incorporação destes componentes $[13,77]$. No processo de refino primário e secundário do aço geralmente utiliza-se fluorita $\left(\mathrm{CaF}_{2}\right) \mathrm{com}$ a finalidade de reduzir o ponto de fusão da escória e melhorar as condições cinéticas para a absorção de inclusões [82]. Acredita-se que os íons flúor sejam responsáveis pela redução da viscosidade de escória pela quebra das cadeias de silicatos (Eq.F) e pela redução da sua tensão superficial.

$$
(: \mathrm{Si}-\mathrm{O}-\mathrm{Si}:)=\mathrm{F}^{-}=\left(\mathrm{Si}-\mathrm{O}^{-}\right)=(\mathrm{F}-\mathrm{Si}:)
$$

A fluorita também intensifica a reatividade da escória, permitindo uma maior solubilidade ou incorporação de $\mathrm{MgO}$ (Fig. 15). Além disso, o efeito da adição de $\mathrm{CaF}_{2}$ pode ser balanceado com uso de agregados eletrofundidos, uma vez que apresentam menor taxa de corrosão em relação aos sinterizados $[8,21]$.

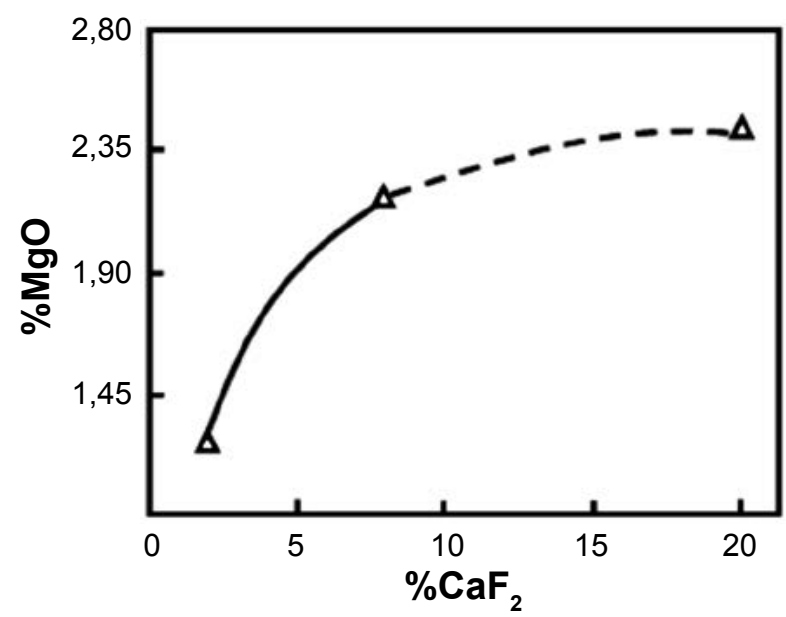

Figura 15: Efeito da adição de fluorita $\left(\mathrm{CaF}_{2}\right)$ na solubilidade de $\mathrm{MgO}$ na escória (Adaptado de [82]).

[Figure 15: Effect of fluorite addition on $\mathrm{MgO}$ solubility in the slag (Adapted from [82]).]

\section{Óxidos de ferro e de alumínio}

Óxidos de ferro $\left(\mathrm{FeO}\right.$ e $\mathrm{Fe}_{2} \mathrm{O}_{3}$ ) são um dos principais componentes das escórias de aciaria e possuem grande impacto na corrosão do refratário, uma vez que influenciam a solubilidade de $\mathrm{MgO}$ e a oxidação do carbono via fase líquida [83, 84]. Estes óxidos apresentam elevada capacidade de formação de solução sólida com $\mathrm{MgO}$, sendo que as fases formadas magnesio-wustita $(\mathrm{MgO} . \mathrm{FeO})$ e magnesio-ferrita $\left(\mathrm{MgO} . \mathrm{Fe}_{2} \mathrm{O}_{3}\right)$ podem ser encontradas na interface refratário/escória. Estas transformações são acompanhadas por mudanças volumétricas e a solução sólida $\mathrm{MgO}-\mathrm{FeO}_{x}$ se torna ainda mais susceptível de ser formada na presença de $\mathrm{CaO}$ e $\mathrm{SiO}_{2}$, acelerando a dissolução dos agregados [17, 84]. Por sua vez, a oxidação do carbono pode ocorrer via fase líquida pelo $\mathrm{FeO}$ (Eq. G), o qual acarreta a formação de uma camada descarbonetada, facilitando a penetração de escória e dissolução de $\mathrm{MgO}$ [24].

$$
\mathrm{FeO}_{(\mathrm{l})}+\mathrm{C}_{(\mathrm{s})} \leftrightarrow \mathrm{Fe}_{(\mathrm{s})}+\mathrm{CO}_{(\mathrm{g})}
$$

A presença de uma quantidade limitada de óxidos de ferro na escória pode ser benéfica para o refratário, uma vez que auxilia na formação da camada densa na superfície do revestimento (Eq. H) $[13,83]$ e pode levar ao aumento na viscosidade do líquido $[65,85]$. 


$$
\mathrm{Mg}_{(\mathrm{g})}+\mathrm{FeO}_{(\mathrm{l})} \leftrightarrow \mathrm{MgO}_{(\mathrm{s})}+\mathrm{Fe}_{(\mathrm{s})}
$$

Escórias com alto teor de $\mathrm{Al}_{2} \mathrm{O}_{3}$ promovem a formação de uma camada de espinélio (de elevada estabilidade e ponto de fusão) na superfície dos agregados ou disperso na estrutura do refratário pela reação com $\mathrm{MgO}[86,87]$. Este composto atua formando uma camada passivadora na superfície dos agregados de $\mathrm{MgO}$, sendo a reatividade do sistema reduzida pela predominância da corrosão indireta no refratário [88]. Assim, quanto maior a concentração de $\mathrm{Al}_{2} \mathrm{O}_{3}$, maior será a formação de espinélio [87-89].

\section{Ensaios de corrosão típicos para refratários $\mathrm{MgO}-\mathrm{C}$}

A simulação das principais solicitações termoquímicas em laboratório, tendo como referência as peculiaridades dos processos e práticas operacionais de cada siderúrgica, é fundamental para seleção dos materiais de forma a otimizar o seu desempenho. Para a análise dos refratários, utilizam-se amostras provenientes do revestimento após o uso industrial (post-mortem) ou de testes de corrosão em laboratórios. No primeiro caso, torna-se difícil de conhecer com exatidão as condições reais a que o material foi submetido, já no segundo não se consegue simular plenamente a realidade operacional. Este contexto cria evidentemente algumas barreiras para compreensão total dos fenômenos de corrosão [16]. As amostras post-mortem são comumente analisadas via microscopia eletrônica de varredura, onde podem ser verificadas algumas das seguintes regiões: escória, zona de reação, zona de transição e refratário $[13,90]$. Por esta técnica é possível avaliar a microestrutura final, bem como as fases presentes em cada região de ataque químico do líquido penetrante. As principais análises em laboratório do desgaste de corrosão de refratários MgO-C são efetuados via cup test, forno rotativo ou forno de indução [91]. O cup test é um ensaio estático em que se adiciona escória em uma cavidade cilíndrica usinada no centro do corpo de prova e este conjunto (escória e refratário) é introduzido em um forno e aquecido até a temperatura de ensaio. Este método não é adequado para simulações da taxa de corrosão por longos tempos, pois o volume do líquido empregado é pequeno, podendo ocorrer a rápida saturação do mesmo. Tanto no forno de indução como no rotativo tem-se a agitação do metal e da escória, sendo esta circulação particularmente importante em sistemas que apresentam reações indiretas (como $\mathrm{MgO}-\mathrm{C}$ ), pois o movimento do líquido pode remover a camada passivadora formada, e assim simular com maior eficiência o processo corrosivo [91, 92]. Para o ensaio em forno rotativo monta-se o cadinho cilíndrico no sentido horizontal com seis peças formando um hexágono (Fig. 16a), onde cada uma delas pode ter composições distintas. $\mathrm{O}$ aquecimento é realizado por uma chama de acetileno e a reatividade da escória é mantida durante todo o ensaio, uma vez que novas adições são realizadas após determinados intervalos de tempo. A vantagem deste método é o baixo custo e a facilidade de desmontagem do sistema após a conclusão do ensaio [91]. Todavia, este método é pouco utilizado nas indústrias refratárias devido à exigência do

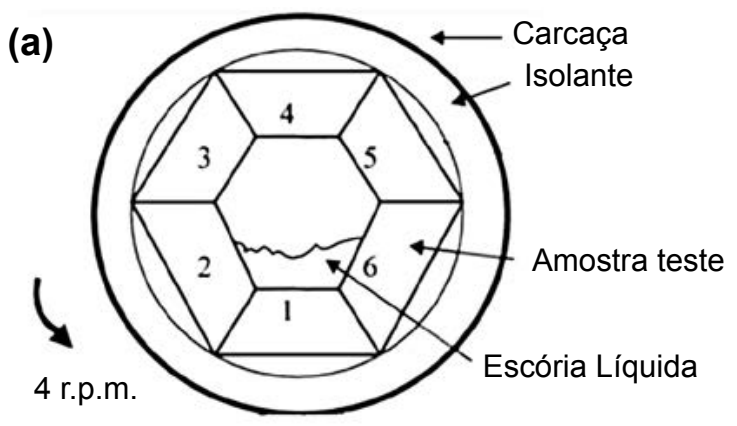

(b)

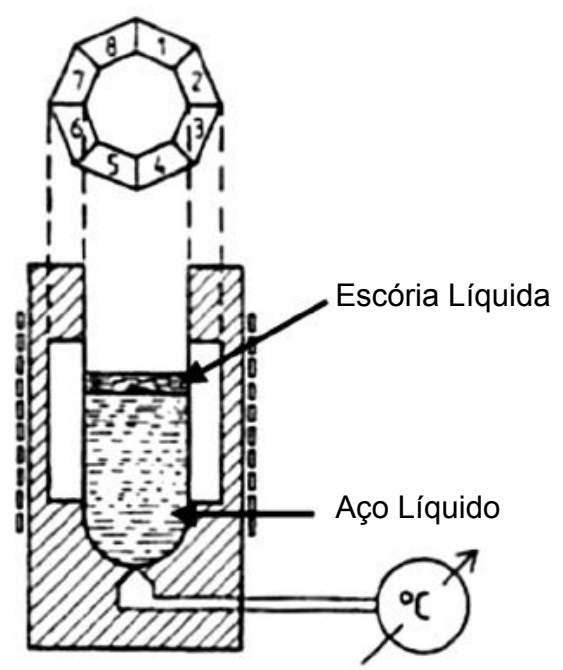

Figura 16: Esquema ilustrativo da montagem dos corpos de prova para a realização do ensaio de corrosão utilizando (a) forno rotativo e (b) forno de indução.

[Figure 16: Schematic drawing of the samples used for corrosion tests: (a) rotary furnace and (b) induction furnace.]

controle da atmosfera para evitar oxidação do carbono nos tijolos contendo carbono.

Nos ensaios em forno de indução são adicionados aço e escória, os quais são fundidos por meio de aquecimento indutivo em cadinhos refratários preparados com tijolos na forma poligonal e no sentido vertical (Fig. 16b). Neste método, o gradiente de temperatura é facilmente controlado e a condição operacional de agitação é simulada pelo efeito indutivo [32, 92]. Similarmente ao forno rotativo, a reatividade do sistema é controlada pela renovação da escória.

Considerando os ensaios dinâmicos, o forno de indução resulta em uma simulação com maior paridade com as condições operacionais a que os refratários da linha de escória estão expostos, entretanto maior energia, tempo e custo são requeridos nestas análises. Assim, normalmente o método utilizado na avaliação da resistência à corrosão dos tijolos está associado a fatores de qualidade da informação necessária e recursos disponíveis.

Aditivos antioxidantes e seu desempenho na inibição da oxidação de carbono

No sistema $\mathrm{MgO}-\mathrm{C}$, o desempenho dos refratários em operação tem relação direta com a oxidação do carbono. 
A consequiência imediata da oxidação é o aumento da porosidade, que irá intensificar o desgaste por meio da perda de resistência mecânica e aumento da penetração de ar e escória. Portanto, os benefícios decorrentes do carbono dependem do controle de sua oxidação sob condições operacionais [93, 94]. Uma alternativa para controlar a oxidação em refratários consiste no recobrimento do mesmo com óxidos $\left(\mathrm{Al}_{2} \mathrm{O}_{3}, \mathrm{SiO}_{2}, \mathrm{TiO}_{2}, \mathrm{ZrO}_{2}\right)$ ou carbeto de silício ( $\mathrm{SiC})$. Porém, outra forma mais efetiva é o uso de antioxidantes, que são substâncias que inibem a reação do carbono com oxigênio por meio da reação com monóxido de carbono ou pela formação de uma camada passivadora na estrutura do refratário [95]. Além disso, estes aditivos geram fases secundárias que apresentam expansão volumétrica e reduzem a porosidade e permeabilidade, inibindo uma posterior difusão do oxigênio no refratário [93, 94]. Os principais antioxidantes utilizados são pós metálicos $(\mathrm{Al}, \mathrm{Si}$, $\mathrm{Mg}$ e Ligas) e compostos a base de boro $\left(\mathrm{B}_{4} \mathrm{C}, \mathrm{ZrB}_{2}, \mathrm{MgB}\right.$ e $\mathrm{CaB}_{6}$ ) [52]. Cada substância atua em diferentes faixas de temperatura e assim, o uso em conjunto de mais de um tipo de antioxidante pode induzir uma proteção mais eficiente para o carbono do refratário [94-96]. Foi comentado que existe um valor ótimo de adição de antioxidantes, entre 3-6\%, pois teores muito elevados podem acarretar no aumento da porosidade do refratário, ocasionando a diminuição da resistência física e química [97].

\section{Alumínio}

O alumínio é o antioxidante mais utilizado na indústria de refratários [70]. Este aditivo inicia sua atuação a partir da reação com o oxigênio, formando $\mathrm{Al}_{2} \mathrm{O}_{3}$ (Eq. I). A $600{ }^{\circ} \mathrm{C}$ uma fina camada de $\mathrm{Al}_{2} \mathrm{O}_{3}$ estará presente na superfície das partículas de alumínio, aprisionando esta fase metálica por um período. Posteriormente, $\mathrm{o} \mathrm{Al}_{(1)}$ poderá ainda reagir com o carbono (Eqs. J e K) levando a formação de $\mathrm{Al}_{4} \mathrm{C}_{3(\mathrm{~s})}$ e $\mathrm{AlN}_{(\mathrm{s})}$ [98-100]. O carbeto de alumínio auxilia na adesão entre magnésia e o carbono, por uma difusão inicial do alumínio nos dois compostos, melhorando a resistência mecânica do material [101].

$$
\begin{aligned}
& 4 \mathrm{Al}_{(\mathrm{s})}+3 \mathrm{O}_{2(\mathrm{~g})} \leftrightarrow 2 \mathrm{Al}_{2} \mathrm{O}_{3(\mathrm{~s})} \\
& 4 \mathrm{Al}_{(\mathrm{l}, \mathrm{g})}+3 \mathrm{C}_{(\mathrm{s})} \leftrightarrow \mathrm{Al}_{4} \mathrm{C}_{3(\mathrm{~s})} \\
& \mathrm{Al}_{4} \mathrm{C}_{3(\mathrm{~s})}+2 \mathrm{~N}_{2(\mathrm{~g})} \leftrightarrow 4 \mathrm{AlN}_{(\mathrm{s})}+3 \mathrm{C}_{(\mathrm{s})}
\end{aligned}
$$

A $1100{ }^{\circ} \mathrm{C}$ o $\mathrm{Al}_{4} \mathrm{C}_{3}$ e o $\mathrm{AlN}$ reagem com o $\mathrm{CO}_{(\mathrm{g})}$ (proveniente da oxidação direta do carbono e que permeia pelo refratário) para formar $\mathrm{Al}_{2} \mathrm{O}_{3(\mathrm{~s})}$. A seguir, até $1300{ }^{\circ} \mathrm{C}$ esta alumina se combinará com $\mathrm{MgO}$ para formar espinélio $\mathrm{MgAl}_{2} \mathrm{O}_{4(\mathrm{~s})}($ Eq. L e M). A formação de espinélio in situ é acompanhada por aumento no volume específico do sólido que resulta em um preenchimento parcial dos poros e redução da entrada dos gases para o interior do material, havendo assim a prevenção da oxidação do carbono [98-103].

Vale ressaltar que a redução do monóxido de carbono $\mathrm{CO}_{(\mathrm{g})}$ a carbono $\mathrm{C}_{(\mathrm{s})}$ contribui para a inibição da oxidação e a formação de produtos contendo $\mathrm{Al}_{2} \mathrm{O}_{3}$, melhorando a resistência mecânica dos materiais refratários [93, 98].

$$
\begin{aligned}
& \mathrm{Al}_{4} \mathrm{C}_{3(\mathrm{~s})}+6 \mathrm{CO}_{(\mathrm{g})} \leftrightarrow 2 \mathrm{Al}_{2} \mathrm{O}_{3(\mathrm{~s})}+9 \mathrm{C}_{(\mathrm{s})} \\
& \mathrm{Al}_{2} \mathrm{O}_{3(\mathrm{~s})}+\mathrm{MgO}_{(\mathrm{s})} \leftrightarrow \mathrm{MgAl}_{2} \mathrm{O}_{4(\mathrm{~s})}
\end{aligned}
$$

O principal problema do uso isolado de $\mathrm{Al}$ metálico é que a fase $\mathrm{Al}_{4} \mathrm{C}_{3}$ é facilmente hidratada em temperatura ambiente, levando a formação de $\mathrm{Al}(\mathrm{OH})_{3}$ (Eq. N), que provoca expansão volumétrica e o possível aparecimento de trincas no material $[52,93]$.

$$
\mathrm{Al}_{4} \mathrm{C}_{3(\mathrm{~s})}+12 \mathrm{H}_{2} \mathrm{O}_{(\mathrm{g})} \leftrightarrow 3 \mathrm{CH}_{4(\mathrm{~g})}+4 \mathrm{Al}(\mathrm{OH})_{3(\mathrm{~s})}
$$

Adegradação de tijolos por meio da hidratação do $\mathrm{Al}_{4} \mathrm{C}_{3(\mathrm{~s})}$ está associada principalmente à quantidade do composto $\mathrm{e}$ ao tempo de exposição ao ar. Quanto maior a quantidade de $\mathrm{Al}$ adicionada ao refratário, maior será o aparecimento de trincas e mais rápido ocorrerá a desintegração da peça. Embora a hidratação não seja prevista para condições como as encontradas com o refratário em operação, essa reação pode ocorrer em baixas temperaturas, representando um problema potencial para equipamentos com operação intermitente, tais como panela de aço, forno elétrico, etc. Acredita-se que o ambiente industrial durante os reparos intermediários do revestimento, que são realizadas após resfriamento, possa contribuir para o fenômeno de hidratação do $\mathrm{Al}_{4} \mathrm{C}_{3(\mathrm{~s})}$. Assim, o uso exclusivo de alumínio não é recomendado para o caso de operações intermitentes ao longo da campanha [62].

\section{Silício}

A atuação do silício metálico tem início a $1200{ }^{\circ} \mathrm{C}$ com a formação de $\mathrm{SiC}$ (Eq. O) [97, 100], que poderá se apresentar na forma de whiskers atuando diretamente na prevenção da oxidação e aumento da resistência mecânica dos refratários [93, 97]. Com aumento de temperatura o $\mathrm{SiC}$ reagirá com o $\mathrm{CO}_{(\mathrm{g})}$ resultando em $\mathrm{SiO}_{2(\mathrm{~s})}$ (Eq. P), que a partir de $1300{ }^{\circ} \mathrm{C}$ poderá ainda levar à formação de forsterita, $\mathrm{Mg}_{2} \mathrm{SiO}_{4(\mathrm{~s})}$ (Eq. Q). Esta última transformação é acompanhada por expansão volumétrica, reduzindo tamanho dos poros abertos da estrutura e favorecendo a resistência química dos tijolos de MgO-C [97, 99, 100].

$$
\begin{aligned}
& \mathrm{Si}_{(\mathrm{s})}+\mathrm{C}_{(\mathrm{s})} \leftrightarrow \mathrm{SiC}_{(\mathrm{s})} \\
& \mathrm{SiC}_{(\mathrm{s})}+2 \mathrm{CO}_{(\mathrm{g})} \leftrightarrow \mathrm{SiO}_{2(\mathrm{~s})}+3 \mathrm{C}_{(\mathrm{s})} \\
& \mathrm{SiO}_{2(\mathrm{~s})}+2 \mathrm{MgO}_{(\mathrm{s})} \leftrightarrow \mathrm{Mg}_{2} \mathrm{SiO}_{4(\mathrm{~s})}
\end{aligned}
$$

No entanto, as reações promovidas por este aditivo atuam no sentido de aumentar a corrosão do refratário, pois: (1) $\mathrm{SiO}_{2}$ precipitado na superfície reage com $\mathrm{MgO}$ formando $\mathrm{Mg}_{2} \mathrm{SiO}_{4(\mathrm{~s})}$ que se dissolve na escória. Após dissolução, ocorre redução na basicidade da fase líquida e, conseqüentemente, aumento da solubilidade de $\mathrm{MgO}$ na 
mesma [104] e (2) o $\mathrm{SiO}_{2}$ livre no interior do refratário pode afetar a relação $\mathrm{CaO} / \mathrm{SiO}_{2}$ e promover aumento da formação de fase líquida [105]. Com isso, o uso isolado de silício metálico como antioxidante não é praticado pelos fornecedores de refratários.

\section{Alumínio + Silício}

A adição conjunta de $\mathrm{Al}$ e $\mathrm{Si}$, resulta na obtenção de resistência mecânica superior àquela verificada para os materiais que contém $\mathrm{Al}$ ou $\mathrm{Si}$ separadamente, sendo este fato atribuído ao aparecimento de uma fase eutética, que diminui a temperatura das reações do sistema, principalmente pela formação de espinélio $\mathrm{MgAl}_{2} \mathrm{O}_{4}$ e forsterita $\mathrm{Mg}_{2} \mathrm{SiO}_{4}$ (Eq. R e S). Adicionalmente, estas fases podem atuar como barreira protetora à oxidação, similarmente à camada densa de $\mathrm{MgO}$ [11, 62]. Assim, a adição de uma liga de composição eutética $\mathrm{Al}+\mathrm{Si}$ resulta boa homogeneidade no sistema $\mathrm{MgO}-\mathrm{C}$ decorrente da proteção mais uniforme ao ataque químico $[12,106]$.

$$
\begin{aligned}
& \mathrm{MgO}_{(\mathrm{s})}+2 \mathrm{Al}_{(\mathrm{s})}+3 / 2 \mathrm{O}_{2(\mathrm{~g})} \leftrightarrow \mathrm{MgO} \cdot \mathrm{Al}_{2} \mathrm{O}_{3(\mathrm{~s})} \\
& 2 \mathrm{MgO}_{(\mathrm{s})}+\mathrm{Si}_{(\mathrm{s})}+\mathrm{O}_{2(\mathrm{~g})} \leftrightarrow 2 \mathrm{MgO} \cdot \mathrm{SiO}_{2(\mathrm{~s})}
\end{aligned}
$$

Além disso, a presença de $\mathrm{Si}$ reduz e/ou inibe a degradação do refratário $\mathrm{MgO}-\mathrm{C}$ devido à formação da fase $\mathrm{Al}_{4} \mathrm{SiC}_{4}$ (Eq. T), que é estável em alta temperatura [11].

$$
\mathrm{Al}_{4} \mathrm{C}_{3}(\mathrm{~s})+\mathrm{SiC}(\mathrm{s}) \leftrightarrow \mathrm{Al}_{4} \mathrm{SiC}_{4(\mathrm{~s})}
$$

Em resumo, os antioxidantes metálicos são fortes agentes redutores e apresentam os benefícios de: (1) aumento da resistência mecânica; (2) formação de fases sólidas in situ; (3) aumento da quantidade de carbono devido a redução química do $\mathrm{CO}_{(\mathrm{g})}$ e (4) formação de uma camada densa de $\mathrm{MgO}_{(\mathrm{s})}, \mathrm{MgAl}_{2} \mathrm{O}_{4(\mathrm{~s})}$ ou outros óxidos estáveis em temperaturas acima de $1200{ }^{\circ} \mathrm{C}[12,18$, 95]. Todavia, deve-se atentar para a propensão à oxidação durante a etapa de produção dos refratários, o que pode inibir o efeito antioxidante destes compostos quando em operação a altas temperaturas nas usinas siderúrgicas [44].

\section{Não-metálicos à base de boro}

$\mathrm{O}$ uso de antioxidantes não metálicos é freqüentemente associado com a formação de fases líquidas (provenientes da reação destes materiais com o oxigênio) e óxidos a partir da interação com os outros componentes do refratário a elevadas temperaturas. Tais líquidos atuam no preenchimento dos poros abertos e, conseqüentemente na prevenção da oxidação do carbono. Todavia, a quantidade utilizada de tais aditivos deve ser otimizada, pois a resistência física e química das composições refratárias podem ser afetadas de maneira negativa a elevadas temperaturas [40]. Nesta classe de antioxidantes destacase aqueles a base de boro (como $\mathrm{B}_{4} \mathrm{C}, \mathrm{CaB}_{6}$ e $\mathrm{ZrB}_{2}$ ). $\mathrm{O} \mathrm{B}_{4} \mathrm{C}$ é considerado o antioxidante mais efetivo na prevenção de carbono, uma vez que adições pequenas já apresentam uma significativa redução da perda deste componente em tijolos de MgO-C. [107, 108]. Este aditivo atua na formação de camada densa na superfície quente do refratário prevenindo a oxidação do carbono $[93,97]$. $\mathrm{O} \mathrm{B}_{4} \mathrm{C}$ pode reagir com o oxigênio em temperaturas inferiores a $600{ }^{\circ} \mathrm{C}(\mathrm{Eq}$. U) [94]. Por outro lado, a aproximadamente a $1000{ }^{\circ} \mathrm{C}$, este material ainda pode reagir com $\mathrm{CO}_{(\mathrm{g})}$ ou $\mathrm{N}_{2(\mathrm{~g})}$ da atmosfera para formar $\mathrm{B}_{2} \mathrm{O}_{3}$ ou $\mathrm{BN}$, respectivamente (Eq. V e W) [93, $96,108]$. No primeiro caso tem-se o aumento de volume e formação de fase líquida, que promove maior densidade do material, por meio do fechamento de poros e recobrimento parcial das partículas [109]. Também a $1000{ }^{\circ} \mathrm{C}$, o $_{2} \mathrm{O}_{3}$ irá reagir rapidamente com o $\mathrm{MgO}$ para formar a fase $3 \mathrm{MgO}$. $\mathrm{B}_{2} \mathrm{O}_{3}$ (Eq. X).

$$
\begin{aligned}
& \mathrm{B}_{4} \mathrm{C}_{(\mathrm{s})}+3 \mathrm{O}_{2(\mathrm{~g})} \leftrightarrow 2 \mathrm{~B}_{2} \mathrm{O}_{3(\mathrm{l})}+\mathrm{C}_{(\mathrm{s})} \\
& \mathrm{B}_{4} \mathrm{C}_{(\mathrm{s})}+6 \mathrm{CO}_{(\mathrm{g})} \leftrightarrow 2 \mathrm{~B}_{2} \mathrm{O}_{3(\mathrm{l})}+7 \mathrm{C}_{(\mathrm{s})} \\
& \mathrm{B}_{4} \mathrm{C}_{(\mathrm{s})}+2 \mathrm{~N}_{2(\mathrm{~g})} \leftrightarrow 4 \mathrm{BN}_{(\mathrm{s})}+\mathrm{C}_{(\mathrm{s})} \\
& \mathrm{B}_{2} \mathrm{O}_{3(\mathrm{l})}+3 \mathrm{MgO}_{(\mathrm{s})} \leftrightarrow 3 \mathrm{MgO} \cdot \mathrm{B}_{2} \mathrm{O}_{3}
\end{aligned}
$$

Na Fig. 17 é apresentada a relação da perda de carbono em função do tipo e quantidade de antioxidantes adicionados ao refratário, considerando as temperaturas de 1300 e $1500{ }^{\circ} \mathrm{C}$. Estes dados também corroboram as análises termogravimétricas que indicam que a perda de carbono no sistema $\mathrm{MgO}-\mathrm{C}$ ocorre na seguinte seqüência: $\mathrm{B}_{4} \mathrm{C}<\mathrm{Al}-\mathrm{Si}<\mathrm{Al}[70,93]$.

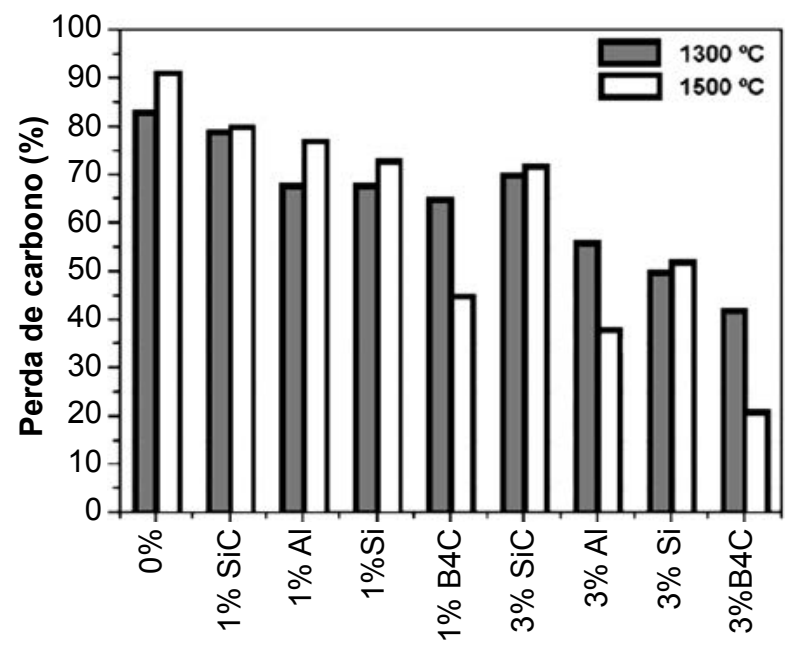

Figura 17: Efeito do tipo e quantidade de antioxidantes em relação a perda de carbono nos refratários $\mathrm{MgO}-\mathrm{C}$ [2].

[Figure 17: Effect of the antioxidants source and content on the $\mathrm{MgO}$-C refractories carbon loss [2].]

$\mathrm{B}_{4} \mathrm{C}$ é um antioxidante efetivo e susceptível a oxidação, porém assim como os demais componentes a base de boro, é caro e a formação das fases líquidas $\left(\mathrm{B}_{2} \mathrm{O}_{3}\right.$ e $\left.3 \mathrm{MgO} \cdot \mathrm{B}_{2} \mathrm{O}_{3}\right)$ a altas temperaturas também diminui a resistência mecânica e à corrosão do refratário $[93,97,110]$. 
Alumínio $+\mathrm{B}_{4} \mathrm{C}$

A presença de alumínio metálico inibe parcialmente o processo de oxidação do $\mathrm{B}_{4} \mathrm{C}$ e reduz a dissolução de $\mathrm{B}_{2} \mathrm{O}_{3}$ pela escória. Acredita-se que o $\mathrm{Al}_{2} \mathrm{O}_{3}$ reage com o $\mathrm{MgO}$ para formar espinélio $\left(\mathrm{MgAl}_{2} \mathrm{O}_{4}\right)$ próximo à superfície do material e, simultaneamente, $\mathrm{o}_{2} \mathrm{O}_{3(1)}$ evapora e reage com $\mathrm{MgO}$, formando fase líquida $\left(3 \mathrm{MgO} \cdot \mathrm{B}_{2} \mathrm{O}_{3}\right)$ acima de $1330{ }^{\circ} \mathrm{C}$, bloqueando efetivamente a oxidação de carbono e acelerando a formação e crescimento de cristais de $\mathrm{MgAl}_{2} \mathrm{O}_{4(\mathrm{~s})}$ [104]. A fase espinélio também atua na redução da quantidade de líquido rico em $\mathrm{Al}$ que pode ser dissolvido pelo metal, diminuindo o processo corrosivo do refratário e a incorporação do mesmo pelo aço. Neste contexto, foi afirmado que os dois antioxidantes juntos têm ação complementares, pois o $\mathrm{Al}$ atua na estrutura local e o $\mathrm{B}_{4} \mathrm{C}$ no total, acarretando melhor eficiência em relação à oxidação [95]. Adicionalmente, a combinação de $\mathrm{Al}$ com carbetos produz compostos complexos, tais como $\mathrm{Al}_{8} \mathrm{~B}_{4} \mathrm{C}_{7}$, que apresentam excelente resistência à hidratação, inibem a oxidação do carbono e favorecem formação da camada densa de $\mathrm{MgO}$. $\mathrm{O} \mathrm{Al}_{8} \mathrm{~B}_{4} \mathrm{C}_{7}$ reduz o monóxido de carbono entre 1000 e $1200{ }^{\circ} \mathrm{C}$ (Eq. Y) $[102,111]$.

$$
\mathrm{Al}_{8} \mathrm{~B}_{4} \mathrm{C}_{7(\mathrm{~s})}+18 \mathrm{CO}_{(\mathrm{g})} \leftrightarrow 4 \mathrm{Al}_{2} \mathrm{O}_{3}+2 \mathrm{~B}_{2} \mathrm{O}_{3(\mathrm{l})}+25 \mathrm{C}_{(\mathrm{s})}(\mathrm{Y})
$$

Experimentalmente foi verificado que amostras de refratários de $\mathrm{MgO}-\mathrm{C}$ contendo $\mathrm{Al}_{8} \mathrm{~B}_{4} \mathrm{C}_{7}$, após testes de oxidação em diferentes temperaturas apresentaram uma estreita camada sem carbono na superfície das peças, confirmando assim a excelente atuação como antioxidante [111]. Todavia, deve-se otimizar a adição de $\mathrm{B}_{4} \mathrm{C}$, pois teores elevados deste material acarretam na formação excessiva de líquido, podendo comprometer os benefícios do uso combinado dos antioxidantes [109]. No intuito de avaliar a resistência à corrosão entre os diversos sistemas de antioxidantes, foram realizados alguns ensaios experimentais e de acordo com os resultados coletados (Fig. 18) a seguinte ordem quanto ao ataque corrosivo foi obtida: $\mathrm{Al}+\mathrm{B}_{4} \mathrm{C}>\mathrm{Al}>\mathrm{B}_{4} \mathrm{C}$ [102].

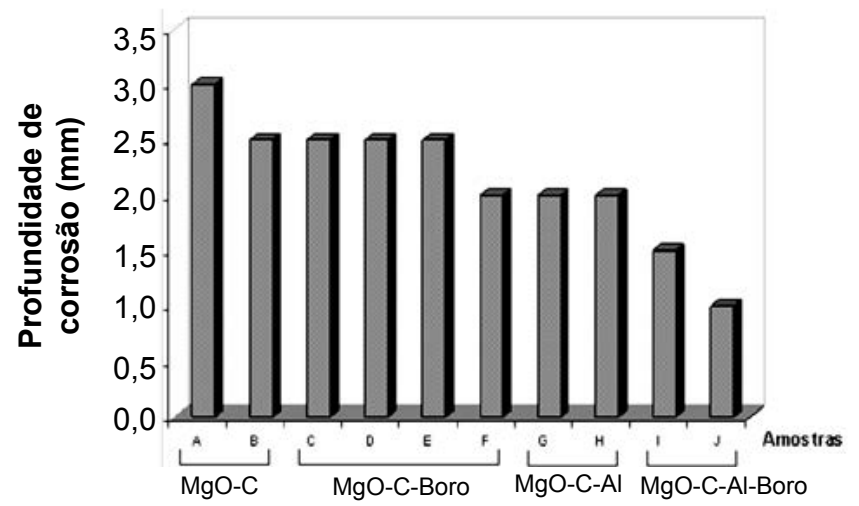

Figura 18: Efeito de diversos antioxidantes na corrosão dos refratários $\mathrm{MgO}-\mathrm{C}$ [102].

[Figure 18: Effect of different antioxidants on $\mathrm{MgO}-\mathrm{C}$ refractory corrosion [102].]
Uso de ferramentas termodinâmicas para a previsão do comportamento de oxidação e corrosão de refratários

Simulações termodinâmicas tem se tornado ferramentas importantes para compreensão das reações e mecanismos de desgaste químico em refratários, pois estas transformações geralmente envolvem fenômenos complexos a temperaturas elevadas e em condições operacionais variadas. Cálculos termodinâmicos são baseados na minimização da energia livre do sistema (para determinada temperatura e pressão), sendo possível deduzir as reações, natureza, proporção e composição química das fases sólidas, líquidas e gasosas na condição de equilíbrio [93, 112]. Com isso, eles auxiliam na previsão dos impactos de fenômenos químicos (como corrosão e oxidação) no desgaste de diversos materiais [113]. Além disso, eles permitem prever o comportamento de matérias-primas e aditivos a elevadas temperaturas, auxiliam a determinação de compatibilidade entre refratário e escória, e fornecem informações para o desenvolvimento contínuo da qualidade e dos processos. Adicionalmente, existe um ganho importante de tempo e custo pela redução de experimentos laboratoriais [31,90]. Uma ferramenta que vem se destacando e sendo amplamente utilizada nos últimos anos na análise de sistemas refratários é o FactSage ${ }^{\mathrm{TM}}$. Este programa foi desenvolvido em conjunto pelos grupos CRCT (Center for Research in Computacional Thermochemistry, Montreal, Canadá) e GTT Technologies (Aachen, Alemanha), o qual possui módulos específicos para a execução de cálculos, assim como banco de dados que permitem os mais variados tipos de avaliações termodinâmicas. Para a execução dos cálculos termodinâmicos dos refratários $\mathrm{MgO}-\mathrm{C}$, alguns autores alertam que cuidados devem ser tomados para tornar mais eficiente e realista as informações obtidas. Lee et al. [112] e Zhang et al. [114] normalmente consideram em suas investigações $100 \mathrm{~g}$ de refratário $\mathrm{MgO}-\mathrm{C}$ e $10 \mathrm{~g}$ de ar, para simular uma atmosfera oxidante. Por outro lado, sugerem que na análise do contato de escórias líquidas com os refratários, os agregados e a matriz devem ser avaliados isoladamente, isso porque existe diferenças entre a reatividade de cada componente. Dessa forma, tem-se uma melhor compreensão dos mecanismos de corrosão atuantes. Também é importante considerar o conceito de composição do líquido local no estudo das interações entre constituintes, uma vez que com a penetração haverá a formação e precipitação de fases sólidas na interface sólido-líquido [32, 90]. Assim, nas simulações deve-se avaliar este processo dinâmico e iterativo (etapa por etapa) de forma a garantir uma maior proximidade entre os resultados obtidos com as observações práticas [113]. Neste sentido, foi estruturarado um procedimento para simulação da interação entre líquidos e refratários no processo de penetração da escória no interior do sólido [113]. Este consiste em iniciar os cálculos a partir da mistura proporcional entre o refratário e escória (50-50\%). Após a reação inicial entre os materiais e, conseqüente modificação da composição da escória, este novo líquido (agora enriquecido com as fases do sólido que se dissolveram) é colocado em contato com a composição original do refratário e um novo cálculo é realizado. A cada nova reação, este mesmo procedimento 
é realizado: a composição atual do líquido é colocada em contato com os dados do refratário inicial.

A desvantagem das simulações é o fato de não fornecerem informações sobre a cinética e distribuição das fases na microestrutura. Além disso, os resultados consideram situações de equilíbrio, as quais são difíceis de serem alcançadas nos sistemas cerâmicos. Assim, para completo entendimento dos mecanismos de reação e desgaste são simultaneamente necessárias as análises termodinâmicas e microestruturais dos materiais [112].

\section{Tendências para o futuro dos refratários MgO-C}

Devido à crescente escassez de matérias-primas de elevada pureza, as indústrias refrataristas têm investido na diversificação de fornecedores e no desenvolvimento de materiais alternativos. O campo de maior destaque é o desenvolvimento e viabilização da nanotecnologia de antioxidantes e carbono para utilização em processos de fabricação de refratários. Acredita-se que esta evolução promoverá além de aumento significativo na resistência química e física destes, também reduzirá a demanda de extração das jazidas, o que aumentará em muito o tempo de vida útil das mesmas. Outro assunto largamente discutido é o impacto ambiental dos refratários $\mathrm{MgO}-\mathrm{C}$ e, neste contexto, os órgãos governamentais vêm pressionando a redução e/ ou eliminação do uso de piche nas composições dos tijolos. Estudos recentes têm avaliado o desenvolvimento da grafitização catalítica de polímeros termofixos, resinas com adição de piche sólido e insumos substitutos a esta aplicação $[52,53]$. As simulações termodinâmicas serão cada vez mais utilizadas como ferramentas de previsão do comportamento de reação das matérias-primas e aditivos antioxidantes, tornando assim precursoras no desenvolvimento de novas formulações refratárias. Adicionalmente, é de se esperar que estes cálculos sejam aprimorados para também auxiliar na melhoria da qualidade dos produtos na siderurgia, por meio do completo entendimento da interação aço-escóriarefratário.

\section{CONSIDERAÇÕES FINAIS}

Atualmente, uma melhor eficiência operacional na produção de aço demanda o desenvolvimento de refratários com desempenho confiável e elevada durabilidade. Para tanto, compreender os mecanismos de desgastes é essencial para o progresso da tecnologia destes materiais e aumento de produtividade nas indústrias siderúrgicas. Adicionalmente, devido à diversificação na carteira de produção das aciarias, existe cada vez mais a necessidade de adequar as propriedades físicas e químicas dos tijolos de acordo com a realidade operacional e qualidade vigentes. Ao longo das últimas décadas, a vida útil dos refratários do sistema $\mathrm{MgO}-\mathrm{C}$ tem sido aprimorada por meio de novas pesquisas e desenvolvimentos tanto no âmbito de utilização de matérias-primas mais nobres, quanto o maior controle das variáveis operacionais que impactam o desempenho do revestimento. Todavia, o desempenho destes materiais não depende somente da qualidade dos insumos, mas também do processo produtivo e de cuidados na operação. Por isso, é fundamental a colaboração e esforço mútuo de clientes, fornecedores e centros de pesquisa para a melhoria contínua e novos desenvolvimentos nesta área.

\section{AGRADECIMENTOS}

Os autores agradecem a ArcelorMittal Monlevade e ao CNPq pelo suporte a esta pesquisa e ao Eng. Eric Yoshimitsu Sako pela revisão.

\section{REFERÊNCIAS}

[1] Y. Naruse, S. Fujimoto, H. Shikano, T. Harada, J. Yoshitomi, M. Hori, M. Kamilde, "Carbon Containing Bricks for Ladle Slag Line", Taikabutsu Overseas 4, 2 (1984) 49-57. [2] H. Jansen, H. Daldrup, "Refractories in Steel Ladles - Materials and Design", Proc. AISTech the Iron and Steel Technology Conf. and Exp., Nashville, EUA (2004) 11691182.

[3] K. Riepl, H. Barthel, "Large-Crystal Magnesia Clinker for Advanced Refractories, an Update and Overview", Proc. Unified Int. Technical Conf. Refractories, Aachen (1991) 97102.

[4] C. G. Aneziris, D. Borzov, G. Schmidt, "Improved Carbon Bonded MgO Materials as Smart Refractories", Proc. Tehran Int. Conf. Refractories (20’04) 56-63.

[5] C. F. Cooper, "Refractory Appl. of Carbon", Trans. J. Brit. Ceram. Soc. (1984) 48-53.

[6] A. Figueiredo, N. Bellandi, A. Vanola, L. Zomboni, "Technological Evolution of Magnesia-Carbon Bricks for Steel Ladles in Argentina", Proc. Unified Int. Technical Conf. Refractories, Cancun, México (2001) 635-643.

[7] C. Alvarez, E. Criado, C. Baudin, "Refractarios de Magnesia-Grafito", Bol. Soc. Esp. Cerám. Vidrio 31, 5 (1992) 397-405.

[8] S. Idicula, "Role of Refractories in Secondary Refining through Ladle Furnace", Proc. Int. Sem. Refractories, Jamshepudr, India (1992) 140-146.

[9] H. Nomura, "Technological Changes and Future Needs of Steel Making Refractories in Japan", J. Tech. Assoc. Refractories 29, 3 (2009) 173-182.

[10] R. Jhunjhunwala, M. M. Sahu, P. C. Padhi, S. P. Idicula, "Advances in Magnesia-Carbon Brick Applications", Proc. Unified Int. Tech. Conf. Refractories, S. Paulo, SP (1993) 391-400.

[11] F. D. Santos, "Mecanismo de Proteção e Corrosão dos Refratários de MgO-C-Aditivos Metálicos", Diss. Mestrado, Universidade Federal de S. Carlos, SP (1991).

[12] G. C. Filho, "Mecanismo de Proteção dos Refratários de Magnésia-Carbono", Diss. Mestrado, Universidade Federal de S. Carlos, SP (1990).

[13] W. E. Lee, S. Zhang, "Melt corrosion of oxide and oxidecarbon refractories", Int. Mater. Rev. 44 (1999) 77-104.

[14] I. Menezes, "Matérias Primas para Refratários Básicos", Anais XVII Cong. Bras. Cerâmica, Salvador, BA (1973) 
$1-34$.

[15] S. Palco, M. Rigaud, T. T. Chen, D. H. H. Quon, B. Martin, H. Ledoussal, "Characterization of the Microstructure of Refractory Grade Magnesia of Different Origins", J. Can. Ceram. Soc. 62, 4 (1993) 253-257.

[16] S. R. Bragança, "Aspectos Teóricos e Práticos sobre a corrosão de Refratários utilizados na Metalurgia", Anais $54^{\circ}$ Cong. Bras. Cerâmica, Foz do Iguaçu, PR (2010) 11421151 .

[17] W. E. Lee, S. Zhang, N. J. Marriot, H. Sarpoolaky, "Influence of Microstructure on Refractories Corrosion", Proc. Unified Int. Tech. Conf. Refractories, Cancun, México (2001) 2-10.

[18] A. Yamaguchi, "Consideration on Improving CorrosionResistance of Refractories", Taikabutsu Overseas 13, 4 (1993) 354-358.

[19] A. Maekwa, M. Geji, M. Tanaka, T. Kitai, K. Furukawa, "Influence of Impurities in Fused Magnesia on Properties of MgO-C Bricks", Taikabutsu Overseas 19, 4 (1999) 26-29.

[20] T. Suruga, "Effect of High Temperature on MgO-C Reaction", Taikabutsu Overseas 18, 4 (1998) 5-10.

[21] K. Tabata, K. Ichikawa, N. Tsukamoto, Y. Tanaka, "The Influence of Slag Composition on the Refractories for Refining Ladle", Taikabutsu Overseas 8, 3, (1988) 36-39.

[22] W. Steinwender, J. Bugajski, "Periclase Crystal Size Importance, Determination, Propagation”, Proc. Unified Int. Tech. Conf. Refractories, Aachen, Alemanha (1991) 91-96. [23] A. Yamaguchi, "Considering the Evaluation and Development of Refractories", Taikabutsu Overseas 17, 4 (1997) 6-12.

[24] S. Takanaga, "Wear of magnesia-carbon bricks in BOF", Taikabutsu Overseas 13, 4 (1993) 8-14.

[25] K. Anan, "Wear of Refractories in Basic Oxygen Furnace (BOF)", J. Tech. Assoc. Refractories 21, 4 (2001) 241-246.

[26] R. A. Landy, Magnesia Refractories, Refractories Handbook, Charles A. Schacht, Marcel Dekker, Inc., New York, EUA (2004) 109-149.

[27] N. Khalili, M. Akbari, S. Roshanfekr, V. K. Marghoussian, J. Javadpour, "The Effect of Magnesia Type on the Properties of Refractories Used by Steel Production Plants in Iran", Proc. Unified Int. Tech. Conf. Refractories, Cancun, México (2001) 6p.

[28] A. Matsuo, S. Miyagawa, K. Ogasahara, M. Yokoi, R. Uchimura, M. Kumagai, "Improvements of $\mathrm{MgO}-\mathrm{C}$ Brick for LD Converter", Taikabutsu Overseas 5, 2 (1985) 3-6.

[29] M. Bavand-Vandchali,F. Golestani-Fard,H. Sarpoolaky, H. R. Rezaie, C. G. Aneziris, "The Influence on in situ spinel formation on microstructure and phase evolution of MgO-C refractories", J. Eur. Ceram. Soc. 28 (2008) 563-569.

[30] P. L. Smith, J. Liddle, J. White, "Equilibrium Relationships of Carbon-Metal Oxide Refractories", Brit. Ceram. Trans. J. 84 (1985) 62-69.

[31] S. Zhang, W. E. lee, "Use of Phase Diagrams in Studies of Refractories Corrosion”, Int. Mater. Rev. 45, 2 (2000) 4158.

[32] W.E. Lee, S.Zhang, "Direct and Indirect Slag Corrosion of Oxide and Oxide-c Refractories", Proc. VII Int. Conf. Molten Slags Fluxes and Salts, Johannesburg, Africa do Sul (2004) 309-319.

[33] K. Matsui, F. Kawano, "Effect of Impurities in Magnesia on Reaction between Magnesia Clinker and Carbon", Taikabutsu Overseas 14, 1 (1994) 3-12.

[34] B. Rand, A. S. Ahmed, V. P. S. Ramos, "The role of carbon in refractories", Proc. Tehran Int. Conf. Refractories (2005) 40-55.

[35] E. M. M. Ewais, "Carbon Based Refractories", J. Ceram. Soc. Japan 112, 10 (2004) 517-532.

[36] C. G. Aneziris, D. Borzov, J. Ulbricht, "MagnesiaCarbon Bricks - A High-Duty Refractory Material", Interceram - Refractories Manual (2003) 22-27.

[37] S. Hocquet, S. André, J. P. Erauw, J. Tirlocq, "Characterization of Oxidation Phenomena in Carbon Containing Refractory Materials for Metallurgy", Proc. Unified Int. Tech. Conf. Refractories, Dresden, Alemanha (2007) 226-229.

[38] M. Tanaka, T. Kitai, "The Influence of Magnesia Particle Size Distribution on the Physical Properties of MgO-C Bricks", Proc.Unified Int. Tech. Conf. Refractories, Kyoto, Japão (1995) 116-123.

[39] P. O. R. C. Brant, B. Rand, "Reactions of Silicon and Aluminium in MgO-Graphite Composites: I - Effects on Porosity and Microstructure", Proc. Unified Int. Tech. Conf. Refractories, Aachen, Alemanha (1991) 247-250.

[40] A. P. Luz, "Concretos Refratários Avançados com Alto Teor de Carbono", Tese Dr., Universidade Federal de S. Carlos, SP (2010).

[41] P. O. R. C. Brant, V. C. Cruz, "Brazilian Flake Graphites for Carbon Containing Refractories", Proc. Unified Int. Tech. Conf. Refractories, S. Paulo, SP (1993) 401-410.

[42] I. Mochida, "Roles of Carbon in Composite Refractories for Better Properties", Taikabutsu Overseas 8, 4 (1988) 3647.

[43] X. Li, M. Rigaud, "Effect of Graphite Quality on Oxidation and Corrosion Resistance of Magnesia-Carbon Refractories", Proc. $2^{\text {nd }}$ Int. Symp. Adv. Refractories Metallurgical Ind., Montreal, Canadá (1996) 95-107.

[44] P.T.Troell,D.J.Michael, "Advances in the Development and Application of Magnesia-Carbon Brick", Proc. Unified Int. Tech. Conf. Refractories, Aachen, Alemanha (1991) 351-356.

[45] S. Chatterjee, R. Eswaran, "Continual Improved Performance MgO-C Refractory for BOF", Proc. Unified Int. Tech. Conf. Refractories, Salvador, BA (2009) 1-4.

[46] H. Jansen, "Bonding of MgO-C Bricks by Catalytically Activated Resin”, Millennium Steel Int. (2007) 95-98.

[47] P. Williams, D. Taylor, H. Leoni, "Advanced Phenolic Resin Binder Systems for Magnesia-Carbon Refractories", Proc. Unified Int. Tech. Conf. Refractories, S. Paulo, SP (1993) 347-359.

[48] L. B. Khoroshavin, V. A. Perepelitsyn, "Binders of the New Generation", Refractories Ind. Ceram. 41, 9 (2000) 309-312.

[49] G. Buchebner, L. Sampayo, V. Samm, P. Blondot, S. 
Peruzzi, P. Boulanger, "ANKERSYN - A New Generation of Carbon-Bonded Magnesia Carbon Bricks", RHI Bull. 1 (2006) 24-27.

[50] S. Zhang, W. E. Lee, "Carbon Containing Castables: Current Status and Future Prospects", Brit. Ceram. Trans. 101, 1 (2002) 1-8.

[51] B. Rand, B. McEnaney, "Carbon Binders from Polymeric Resins and Pitch. Part I - Pyrolysis Behaviour and Structure of the Carbons", Brit. Ceram. Trans. J. 84, 5 (1985) 147-165.

[52] C. S. Bitencourt, V. C. Pandolfelli, "Resinas Termofixas e a Produção de Refratários Contendo Carbono: Base Teórica e Insights para Futuros Desenvolvimentos", Cerâmica 59, 349 (2013) 1-26.

[53] C. S. Bitencourt, V. C. Pandolfelli, "Refratários Contendo Carbono: Propriedades, Características e Variáveis em sua Composição", Cerâmica 59, 349 (2013) 84-114.

[54] E. J. Estrada, L. J. González, D. G. Campos, “Industrial Performance of MgO-C Refractories with Different Type of Binders used in Electric Arc Furnaces", Proc. Unified Int. Tech. Conf. Refractories, Salvador, BA (2009) 4p.

[55] D. Borzov, J. Ulbricht, W. T. Schulle, “Technological and Environmental Comparison of Different Carbon-Binders for MgO-C Refractories", Proc. $44^{\circ}$ Int. Coll. Refractories, Cancun. México (2001) 50-52.

[56] A. Gardziella, J. Suren, M. Belsue, "Carbon from Phenolic Resins: Carbon Yield and Volatile Components Recent Studies", Interceram 41, 7 (1992) 461-467.

[57] T. Kuffa, G. Sucik, D. Hrsak, "The Influence of Carbon Materials on the Properties of MgO Refractories", Materiali Tehnologije 39, 6 (2005) 211-213.

[58] H. Jansen, C. G. Aneziris, M. Hampel, Y. W. Li, "Microstructure and Mechanical Behaviour of MagnesiaCarbon Bricks Bonded by Catalytically Activated Resins", Proc. of Unified Int. Technical Conf. Refractories, Dresden, Alemanha (2007) 38-41.

[59] W. Klein, W. Münchberg, R. Prange, I. Stradmann, "Lining Conceptions for Ladle Used in Secondary Metallurgy Based on Specific Properties of Refractory Materials", Interceram 40, 2 (1991) 89-93.

[60] W. Lin, O. Nomura, R. Nakamura, S. Uchida, E. Mori, "Decarbonization Behavior of Graphite-Containing Refractories by Molten Steel", Taikabutsu Overseas 19, 4, (1999) 15-24.

[61] Y. Wei, N. Li, W. Xie, B. Zhao, J. Li, "Corrosion of Magnesia Carbon Refractory at Steel-Slag Boundary during Oriented Silicon Steelmaking”, Proc. of Unified Int. Technical Conf. Refractories, Salvador (2009) 5p.

[62] J. C. V. Castro, "Influência de Aditivos Metálicos sobre as Propriedades dos Tijolos Refratários de MagnésiaCarbono Ligados a Piche", Diss. Mestrado, Universidade Federal de S. Carlos, SP (1990).

[63] M. A. Quintela, F. D. Santos, C. A. Pessoa, J. A. Rodrigues, V. C. pandolfelli, "MgO-C Refractories for Steel Ladles Slag Line", Refractories Applications News 11, 5 (2006) 15-19.

[64] W. Lee, T. S. Lee, S. Zhang, "Direct and Indirect
Corrosion of $\mathrm{MgO}$ and $\mathrm{MgO}-\mathrm{C}$ Refractories", Proc. Unified Int. Technical Conf. Refractories, Berlin (1999) 367-368.

[65] A. Yamaguchi, "Control of Oxidation-Reduction in MgO-C Refractories", Taikabutsu Overseas 4, 1 (1984) 3237.

[66] M. A. Quintela, C. A. Pessoa, A. P. Salgado, “Análise de Desgaste de Refratários para Convertedor", Tecnol. Metal. Mater. Miner. 6, 1 (2009) 36-40.

[67] N. C. Lubaba, B. Rand, N. H. Brett, "Microstructure and Strength of MgO-Carbon Composite Refractory Materials", Brit. Ceram. Trans. J. 88 (1989) 47-54.

[68] M. Labadie, S. Camelli, M. L. Dignani, A. Vázquez, "Resistencia a la Oxidación de Ladrillos de MgO-C Bajo Diferentes Atmosferas", Anais $36^{\circ}$ Cong. Asoc. Latinoam. Fabricantes Refractarios, Lima, Peru (2010) 15p.

[69] O. Volkova, B. Sahebkar, J. Hubalkova, C. G. Aneziris, P. R. Scheller, "Ladle Heating Procedure and its Influence on the Oxidation Resistance of MgO-C Refractories", Proc. Unified Int. Technical Conf. Refractories, Dresden, Alemanha (2007) 476-479.

[70] A. S. Gokce, C. Gurcan, S. Ozgen, S. Aydin, "The Effect of Antioxidants on the Oxidation Behaviour of MagnesiaCarbon Refractory Bricks", Ceram. Int. 34 (2008) 323-330. [71] A. Yamaguchi, Y. J. Kun, "Formation and Expansion of Open Pore in Carbon-Containing Refractories and Their Prevention", Taikabutsu Overseas 14, 1 (1994) 20-25.

[72] A. R. Hanifi, A. Eilaghi, A. Salary, F. Golestani-Fard, W. L. Headrick, "FEM Simulation of the Thermo-Mechanical Behaviour of Refractories Used in Ladles of Esfahan Steel Company”, Proc. Unified Int. Technical Conf. Refractories, Orlando, EUA (2005).

[73] S.A. Franklin, B .J. S. Tucker, "Hot Strength and Thermal Shock Resistance of Magnesia-Carbon Refractories", Brit. Ceram. Trans. 94, 4 (1995) 151-156.

[74] D. A. Bell, "First Heat-Up of Ladle Linings", Proc. Unified Int. Technical Conf. Refractories, Berlin, Alemanha (1999) 292-294.

[75] D. A. Brosnan, "Corrosion of Refractories, Refractories Handbook", C. A. Schacht, Marcel Dekker, Inc., New York, EUA (2004) 39-77.

[76] J. P. Ferreira, S. R. Bragança, “Avaliação da Escória de FEA e FP em Relação à Vida Útil dos Refratários", Anais $54^{\circ}$ Cong. Bras. Cerâmica, Foz do Iguaçu, PR (2010) 11181129 .

[77] T. A. Ávila, R. S. Freire, G. F. B. L. Silva, R. N. Borges, "Design of Slags Compatible with Refractories Systems", Proc. Unified Int. Technical Conf. Refractories, Salvador, BA (2009) 6p.

[78] J. Poirier, M. L. Bouchetou, P. Prigent, J. Berjonneau, "An Overview of Refractory Corrosion: Observations, Mechanisms and Thermodynamic Modeling", Refractories Appl. Trans. 3, 2 (2007) 2-12.

[79] M. A. V. Ende, M. Guo, P. T. Jones, B. Blanpain, P. Wollants, "Wear Mechanisms of $\mathrm{MgO}-\mathrm{C}$ Refractories in Contact with MnO-Rich Stainless Steel Slags", Ceram. Int. 35 (2009) 2203-2212.

[80] J. Liu, M. Guo, P. T. Jones, F. Verhaeghe, B. Blanpain, 
P. Wollants, "In Situ Observation of the Direct and Indirect Dissolution of $\mathrm{MgO}$ Particles in $\mathrm{CaO}-\mathrm{Al}_{2} \mathrm{O}_{3}-\mathrm{SiO}_{2}$ Based Slags", J. Eur. Ceram. Soc. 27 (2007) 1961-1972.

[81] S. Akkurt, H. D. Leigh, "Corrosion of MgO-C Ladle Refractories", Ceram. Bull. 34 (2003) 32-40.

[82] P. Zhang, S. Seetharaman, "Dissolution of $\mathrm{MgO}$ in $\mathrm{CaO}-$ "FeO"-CaF2-SiO2 Slags Under Static Conditions", J. Am. Ceram. Soc. 77, 4 (1994) 970-976.

[83] J. Kwong, J. P. Bennet, "Extending MgO Refractory Service Life By Using an MgO Saturated Slag in the Electrical Arc Furnace", Proc. Unified Int. Technical Conf. Refractories, Salvador, BA (2009) 5p.

[84] K. Takeda, K. Nonobe, S. Takanaga, H. Takahashi, "Corrosion Mechanism of Magnesia-Carbon Brick by CaO$\mathrm{SiO}_{2}-\mathrm{Fe}_{2} \mathrm{O}_{3}$ Slag", J. Technical Assoc.tion of Refractories 21, 1 (2001) 51-56.

[85] K. Mukai, Z. Tao, K. Goto, Z. Li, T. Takashima, "Insitu X-ray Observation and Microstructural Analysis on Slag Penetration into MgO Refractories", J. Technical Association Refractories 21, 1 (2001) 3-10.

[86] T. Matsui, K. Hiragushi, T. Ikemoto, K. Sawano, "Corrosion of Magnesia Refractory Brick by Silicate Slag", J. Technical Association Refractories 23, 1 (2003) 11-14. [87] T. Matsui, K. Hiragushi, T. Ikemoto, K. Sawano, "Penetration Behavior of Silicate Slag into Magnesia Refractory Bricks", J. Technical Association Refractories 22, 4 (2002) 302-309.

[88] Y. Jitsumori, T. Yoshida, A. Yamaguchi, "Effect of Starting Materials Characteristics on Microstructures and Properties of Magnesia Carbon Refractories", Proc. Unified Int. Technical Conf. Refractories, Kyoto (1995) 140-147.

[89] P. Blumenfeld, M. Puillet, J. Lorgeril, D. Verelle, "Effect of Service Conditions on Wear Mechanisms of Steel Ladle Refractories", Proc. Unified Int. Technical Conf. Refractories, Dresden (2007) 213-219.

[90] J. Poirier, F. Qafssaoui, J. P. Ildefonse, M. L. Bouchetou, "Analysis and Interpretation of Refractory Microstructures in Studies of Corrosion Mechanisms by Liquid Oxides", J. European Ceram. Soc. 28 (2008) 1557-1568.

[91] M. Tanaka, "Methods of Evaluating the Corrosion Resistance of MgO-C Bricks", J. Technical Association Refractories 23, 2 (2003) 130-133.

[92] J. Pötschke, C. Brüggmann, "Some Corrosion Phenomena in an Induction Furnace", Proc. Unified Int. Technical Conf. Refractories, Salvador (2009) 5p.

[93] A. P. Luz, V. C. Pandolfelli, "Artigo Revisão: Atuação dos antioxidantes em refratários contendo carbono", Cerâmica 53, 328 (2007) 334-344.

[94] E. V. Krivokorytov, N. A. Makarov, N. V. Kononov, B. I. Polyak, "Effect of Antioxidants on the Properties of Unfired Carbon-Bearing Refractories", Refractories Ind. Ceram. 40, 11 (1999) 529-533.

[95] M. Rigaud, P. Bombard, X. Li, B. Guéroult, "Phase Evolution in Various Carbon-Bonded Basic Refractories", Proc. Unified Int. Technical Conf. Refractories, S. Paulo (1993) 360-371.

[96] T. Suruga, "Effect of Mg-B Material Addition to
MgO-C Bricks", Taikabutsu Overseas 15, 2 (1995) 25-31.

[97] S. Zhang, N. J. Marriot, W. E. Lee, "Thermochemistry and microstructures of $\mathrm{MgO}-\mathrm{C}$ refractories containing various antioxidants", J. Eur. Ceram. Soc. 21 (2001) 10371047.

[98] K. Ichikawa, H. Nishio, O. Nomura, Y. Hoshiyama, "Suppression Effects of Aluminum on Oxidation of MgO-C Bricks", Taikabutsu Overseas 15, 2 (1995) 21-24.

[99] A. Watanabe, H. Takahashi, S. Takanaga, N. Goto, K. Anan, M. Uchida, "Behavior of Different Metals Added to MgO-C Bricks", Taikabutsu Overseas 7, 2 (1987) 17-23.

[100] K. Watanabe, K. Yabuta, H. Okamoto, H. Yamamoto, "Oxidation Behavior of MgO-C Bricks with Various Additives", Proc. Unified Int. Technical Conf. Refractories, Kyoto (1995) 100-107.

[101] S. Uchida, K. Ichikawa, "High Temperature Properties of Unburned MgO-C Bricks Containing Al and Si Powders", J. Am. Ceram. Soc. 81, 11 (1998) 2910-2916.

[102] K. Hunold, J. Pötschke, M. Thiesen, "Effect of BoronContaining Antioxidants on the Reaction between MgO-C Bricks, Molten Steel and Slag”, Proc. Unified Int. Technical Conf. Refractories, Berlin (1999) 316-319.

[103] J. Maripavana, B. B. Argent, B. Rand, "Reactions of Silicon and Aluminium in MgO-Graphite Composites: II - Reaction Products", Proc. Unified Int. Technical Conf. Refractories, Aachen (1991) 251-253.

[104] S. Zhang, W. E. Lee, "Influence of additives on corrosion-resistance and corroded microstructures of MgO-C refractories", J. Eur. Ceram. Soc. 21 (2001) 23932405.

[105] K. Tamaki, J. Yoshitomi, M. Harada, "Slag Corrosion Resistance and Slag Coating of Magnesia-Lime-Carbon Bricks", Taikabutsu Overseas 17, 3 (1997) 18-23.

[106] A. V. Mozzherin, V. A. Musevich, A. P. Duka, A. P. Margishvili, A. A. Paivin, V. V. Kazakov, "The Design and Resistance Evolution of 150-ton Ladles Lining", Refractories Ind. Ceram. 50, 1 (2009) 1-9.

[107] K. Hunold, "Boron compounds in MgO-C bricks", Int . Ceram. 1 (1998) 2-6.

[108] M. Itakusu, K. Kouno, K. Harima, S. Tsuboi, "Development and Application of MgO-C Brick Restrained Deterioration of Microstructure at High Temperature", Proc. Unified Int. Technical Conf. Refractories, Osaka (2003) 408-410.

[109] P. O. R. C. Brant, W. A. Lima, C. A. Groenner, "Development of High Erosion and Corrosion Resistance MgO-C Bricks for BOF Applications", Proc. Unified Int. Technical Conf. Refractories (1993) 462-471.

[110] K. Takeuchi, S. Yoshida, S. Tsuboi, "Gas Phase Oxidation of MgO-C Bricks", J. Technical Association Refractories 23, 4 (2003) 276-279.

[111] T. Wang, A. Yamaguchi, "Antioxidation Behavior and Effect of $\mathrm{Al}_{8} \mathrm{~B}_{4} \mathrm{C}_{7}$ Added to Carbon-Containing Refractories", J. Ceram. Soc. Japan 108, 9 (2000) 818-822.

[112] W. Lee, B. B. Argent, S. Zhang, "Complex Equilibria in Refractories Design and Use", J. American Ceram. Soc. 85, 12 (2002) 2911-2918. 
[113] A.P. Luz, V. C. Pandolfelli, "Simulação termodinâmica e sua aplicação na avaliação do desempenho de materiais refratários", Cerâmica 57, 343 (2011) 294-304.
[114] S. Zhang, H. Sarpoolaky, N. J. Marriott, W. E. Lee, "Penetration and corrosion of magnesia grain by silicate slags", Brit. Ceram. Trans. 99, 6 (2000) 248-255.

(Rec. 09/10/2011, Ac. 14/01/2012) 